\title{
A PIV Study of Slotted Air Injection For Jet Noise Reduction
}

Brenda S. Henderson and Mark P. Wernet

Glenn Research Center, Cleveland, Ohio 


\section{NASA STI Program . . . in Profile}

Since its founding, NASA has been dedicated to the advancement of aeronautics and space science. The NASA Scientific and Technical Information (STI) program plays a key part in helping NASA maintain this important role.

The NASA STI Program operates under the auspices of the Agency Chief Information Officer. It collects, organizes, provides for archiving, and disseminates NASA's STI. The NASA STI program provides access to the NASA Aeronautics and Space Database and its public interface, the NASA Technical Reports Server, thus providing one of the largest collections of aeronautical and space science STI in the world. Results are published in both non-NASA channels and by NASA in the NASA STI Report Series, which includes the following report types:

- TECHNICAL PUBLICATION. Reports of completed research or a major significant phase of research that present the results of NASA programs and include extensive data or theoretical analysis. Includes compilations of significant scientific and technical data and information deemed to be of continuing reference value. NASA counterpart of peer-reviewed formal professional papers but has less stringent limitations on manuscript length and extent of graphic presentations.

- TECHNICAL MEMORANDUM. Scientific and technical findings that are preliminary or of specialized interest, e.g., quick release reports, working papers, and bibliographies that contain minimal annotation. Does not contain extensive analysis.

- CONTRACTOR REPORT. Scientific and technical findings by NASA-sponsored contractors and grantees.
- CONFERENCE PUBLICATION. Collected papers from scientific and technical conferences, symposia, seminars, or other meetings sponsored or cosponsored by NASA.

- SPECIAL PUBLICATION. Scientific, technical, or historical information from NASA programs, projects, and missions, often concerned with subjects having substantial public interest.

- TECHNICAL TRANSLATION. Englishlanguage translations of foreign scientific and technical material pertinent to NASA's mission.

Specialized services also include creating custom thesauri, building customized databases, organizing and publishing research results.

For more information about the NASA STI program, see the following:

- Access the NASA STI program home page at http://www.sti.nasa.gov

- E-mail your question via the Internet to help@ sti.nasa.gov

- Fax your question to the NASA STI Help Desk at $443-757-5803$

- Telephone the NASA STI Help Desk at 443-757-5802

- Write to: NASA Center for AeroSpace Information (CASI) 7115 Standard Drive Hanover, MD 21076-1320 
NASA/TM-2012-217251

\section{A PIV Study of Slotted Air Injection For Jet Noise Reduction}

Brenda S. Henderson and Mark P. Wernet

Glenn Research Center, Cleveland, Ohio

Prepared for the

17th Aeroacoustics Conference

cosponsored by the American Institute of Aeronautics and Astronautics and the Confederation of European Aerospace Societies

Portland, Oregon, June 5-8, 2011

National Aeronautics and

Space Administration

Glenn Research Center

Cleveland, Ohio 44135 


\section{Acknowledgments}

The authors thank the engineers and technicians in the LSAWT and the AAPL for assisting with the experiments. The nozzles were designed in cooperation with Goodrich Aerostructures. The authors thank Alan Douglas and Harry Haskin for leading the mechanical design. This work was supported by the Subsonic Fixed Wing Project and Supersonics Project in the Fundamental Aeronautics Program.

Trade names and trademarks are used in this report for identification only. Their usage does not constitute an official endorsement, either expressed or implied, by the National Aeronautics and Space Administration.

This work was sponsored by the Fundamental Aeronautics Program at the NASA Glenn Research Center.

Level of Review: This material has been technically reviewed by technical management.

Available from

NASA Center for Aerospace Information 7115 Standard Drive

Hanover, MD 21076-1320
National Technical Information Service 5301 Shawnee Road Alexandria, VA 22312 


\title{
A PIV Study of Slotted Air Injection For Jet Noise Reduction
}

\author{
Brenda S. Henderson and Mark P. Wernet \\ National Aeronautics and Space Administration \\ Glenn Research Center \\ Cleveland, Ohio 44135
}

\begin{abstract}
Results from acoustic and Particle Image Velocimetry (PIV) measurements are presented for single and dual-stream jets with fluidic injection on the core stream. The fluidic injection nozzles delivered air to the jet through slots on the interior of the nozzle at the nozzle trailing edge. The investigations include subsonic and supersonic jet conditions. Reductions in broadband shock noise and low frequency mixing noise were obtained with the introduction of fluidic injection on single stream jets. Fluidic injection was found to eliminate shock cells, increase jet mixing, and reduce turbulent kinetic energy levels near the end of the potential core. For dual-stream subsonic jets, the introduction of fluidic injection reduced low frequency noise in the peak jet noise direction and enhanced jet mixing. For dual-stream jets with supersonic fan streams and subsonic core streams, the introduction of fluidic injection in the core stream impacted the jet shock cell structure but had little effect on mixing between the core and fan streams.
\end{abstract}

\section{Introduction}

$\mathrm{M}$ ANY jet noise reduction concepts such as mechanical chevrons (serrations at the nozzle trailing edge that deflect into the flow) rely on enhanced jet mixing for noise reduction. Most of these devices are passive and remain deployed throughout the aircraft mission introducing thrust losses during all phases of operation. An attractive alternative is the fluidic chevron produced by injected air at the nozzle trailing edge that is deployed only when needed, thus limiting overall performance penalties. However, fluidic injection systems are plagued with implementation challenges most commonly in the form of high pressure air requirements (often in excess of 700 $\mathrm{kPa}$ ). While these high-pressure systems allow for noise reduction with realistic injection mass flow rates (on the order of a fraction of a percent of the core mass flow rate), the required pressures are well beyond those currently available on aircraft ${ }^{1}$. Modifications to the jet plume and the impact on far-field noise as a result of high-pressure injection is relatively well understood due to the large number of acoustic and flow-field studies presented in the literature ${ }^{2,3}$. Conversely, low pressure injection systems have received little attention with only a few studies investigating noise reduction potential ${ }^{4,5}$. Accompanying flow-field studies are non-existent and, therefore, the injection-jet plume interaction process is not well understood. The current study uses Particle Image Velocimetry (PIV) to investigate jet plume modifications produced by a low-pressure air injection system with slotted injectors.

A jet injected into cross flow (the main jet) produces a counter-rotating vortex pair ${ }^{6}$. The vortex pair is bent by the main jet and produces a longitudinal vortex pair. For multiple injectors, the impact of the injected flow on the main jet depends on the injection system configuration and operating pressure. For high-pressure (often in excess of $700 \mathrm{kPa}$ ) injection systems with multiple circular injectors (often referred to as microjets), the longitudinal vortex pairs transfer low-momentum ambient fluid to the high-momentum main jet ${ }^{2}$. Increases in potential core length with the introduction of microjets have been reported ${ }^{7,8}$ (indicating reduced mixing compared to that of the baseline case) and are an indication that noise reduction is achieved through a different mechanism than that associated with the mechanical chevron. Decreased ${ }^{7,8,9}$ and increased ${ }^{3,10}$ (over that of the baseline jet) peak turbulence levels have been reported for microjet injection with the apparent discrepancy in reported results due to the measurement location and the injection system configuration and operating pressure. For slotted injection systems using pressures below those often used in microjets, only numerical studies have investigated the injector-main jet interaction ${ }^{11,12}$. These studies have shown that the length of the main jet potential core is reduced by the introduction of fluidic injection ${ }^{12}$, a result indicating that slotted, low-pressure injectors may reduce noise through a mechanism (enhanced mixing) related to that of the mechanical chevron. However, experiments are needed to validate these numerical studies. 
Previous investigations with low-pressure systems have shown that noise reduction can be achieved in dual stream subsonic jets and single stream supersonic jets. For dual-stream jets, noise reduction is achieved with core and a combination of core and fan-stream injectors ${ }^{5,13}$ (for both circular and slotted injectors). For single stream supersonic jets, fluidic injection reduces broadband shock noise ${ }^{14}$. Limited benefit has been found with fluidic injection used on dual-stream jets with supersonic fan streams and transonic core streams ${ }^{14}$. Flow-field data are required to fully understand the impact of the fluidic chevrons on the jet plume and the resulting acoustic radiation.

The current study uses two-component and stereo PIV to investigate the impact of slotted, low-pressure, fluidic injection on subsonic and supersonic jets. Single and dual-stream jets are investigated.

\section{Experimental Approach}

The acoustic experiments were conducted in the Low Speed Aeroacoustic Wind Tunnel (LSAWT) at the NASA Langley Research Center shown in Fig. 1. A $1.4 \mathrm{~m} \mathrm{x} 1.4 \mathrm{~m}$ square tunnel nozzle exhausts into a $10.4 \mathrm{~m}$ long test cell with a $5.2 \mathrm{~m} \times 5.2 \mathrm{~m}$ cross section, providing a simulated flight stream with Mach numbers up to 0.32 . The floor, ceiling, and walls are covered with fiberglass wedges. The Jet Engine Simulator (JES) located in center of the flight stream, consists of co-annular streams used to simulate the exhaust of core and fan stream turbo-fan engines. Each stream is equipped with an electric pre-heater and a propane-fired, sudden-expansion burner to achieve engine temperatures of commercial and military aircraft engines.

The acoustic results presented here were obtained from a 28-microphone sideline array located $3.7 \mathrm{~m}$ from the centerline of the JES (see Fig. 1). Microphone calibrations including sensitivity, actuator, and diffraction corrections have been made. In addition, the data have been corrected for shear layer effects using Amiet's ${ }^{15}$ corrections and for atmospheric absorption ${ }^{16}$. The narrowband spectra have a bandwidth of $25.63 \mathrm{~Hz}$ and are presented for the FAA noise certification reference conditions ( $1 \mathrm{~atm}, 77^{\circ} \mathrm{F}, 70 \%$ relative humidity).

The PIV experiments were conducted in the Aero-Acoustic Propulsion Laboratory (AAPL) at the NASA Glenn Research Center shown in Fig. 2. The AAPL is a $20 \mathrm{~m}$ radius geodesic dome treated with acoustic wedges. Within the AAPL is the Nozzle Acoustic Test Rig (NATR) which produces a $1.3 \mathrm{~m}$ diameter simulated forward flight stream (free jet) reaching Mach numbers of 0.35 and contains the High Flow Jet Exit Rig (HFJER), a dual-stream jet engine simulator capable of replicating most commercial turbo-fan engine temperatures and pressures. ${ }^{17}$

A representative $1 / 9^{\text {th }}$ scale, bypass ratio (BPR) 5 nozzle system with a pylon and external plug was used in the experiments (see Fig. 3). Three core nozzles (two air injection nozzles and one baseline nozzle) each with a diameter equal to $12.9 \mathrm{~cm}$ and an area equal to $70.8 \mathrm{~cm}^{2}$ and a $24.0 \mathrm{~cm}$ fan nozzle with an area equal to $188 \mathrm{~cm}^{2}$ were used in the study. For each air injection nozzle, air was delivered to a common plenum in the nozzle through a tube embedded in the pylon as shown in Fig. 4. Six contoured injection passages downstream of the plenum were used to deliver air to injection slots at the trailing edge of the nozzle. The slots were on the core stream side of the nozzle allowing air to exhaust into the core stream. One of the air injection nozzles (identified as the "steep" injection nozzle) and had an injection angle (angle between the injection passage and the core nozzle flow at the nozzle trailing edge) of $45^{\circ}$ and the other air injection nozzle (identified as the "shallow" injection nozzle) had an injection angle of $15^{\circ}$. The trailing edge thicknesses of the injection nozzles were non-uniform due the injection passages as shown in Fig. 3. The baseline core nozzle had a uniform trailing edge thickness of $0.9 \mathrm{~mm}$ and no injection passages. The angle between the pylon and microphone axis was equal to $122^{\circ}$ for all acoustic experiments.

Two types of PIV experiments were conducted: (1) two-component streamwise experiments and (2) cross-stream stereo PIV experiments. For all PIV studies, Redlake ES1 1000 cameras with $2.6 \mathrm{~K}$ x 4K CCD arrays were used to record images. For the streamwise experiments, two cameras, each with a $380 \mathrm{~mm}$ x $325 \mathrm{~mm}$ field of view, were used in a side-by-side configuration with a $28 \mathrm{~mm}$ overlap between camera images. The laser light sheet (created with a $400 \mathrm{~mJ}$ per pulse, $532 \mathrm{~nm}$, dual-head Nd-YAG laser) illuminated the jet centerline and was traversed downstream incrementally to image a total of 18 core nozzle diameters. Figure 5 shows the two light sheet orientations used in the experiments. For the core air injection nozzles, light-sheet orientation 1 passed through one injection port on the side opposite to the pylon. The light sheet was located slightly behind (relative to the camera viewing side of the jet) the tip of the pylon for light sheet orientation 2 and no injection passages were illuminated. In the cross-stream experiments, the laser light sheet illuminated cross-stream planes in the jet and images were acquired at $1.2 D, 1.6 D, 2 D, 2.4 D, 3.4 D, 4.4 D, 5.4 D, 7.8 D, 10.3 D, 13.2 D$, and $16 D$ downstream of the core nozzle trailing edge where $D$ is the diameter of the core nozzle. Only the lower half of the jet was imaged due to the pylon obstructing images near the nozzle exit. The first cross-plane (1.2D) was just downstream of the nozzle plug. The field of view for the cameras was $400 \mathrm{~mm}$ x $325 \mathrm{~mm}$. For all PIV experiments, the core stream, fan stream, and injection flow were seeded with $0.7 \mu \mathrm{m}$ aluminum oxide particles. The core and fan streams were seeded using a pH 
stabilized dispersion of aluminum oxide in ethanol. The air injection stream was seeded using a fluidized bed. The free jet flight stream was seeded with Rosco Delta 3000 foggers with $0.25-0.6 \mu \mathrm{m}$ particles.

For the stereo PIV experiments, the 2-D vector maps from the Left and Right cameras were generated using a multi-pass processing approach. The processing strategy used an initial pass with $64 \times 64$ pixel subregions on 32 pixel centers followed by 6 passes (using simulated annealing) at 32x32 pixel subregions on 16 pixel centers, followed by two final passes using subregion distortion processing. Symmetric Phase Only Filtering was used on the cross-stream data sets to reduce the effect of flare light from the model.

All PIV surveys used 400 image pairs per axial station, yielding 400 velocity vector maps at each axial station. The velocity vector maps were then ensemble averaged to compute the first and second order statistics. Hard velocity cutoff limits and Chauvenet's Criteria were used to remove outliers.

The conditions used in the experiments are shown in Table 1. The Nozzle Pressure Ratio (NPR) is the ratio of the stagnation pressure of the jet to the ambient pressure. The Total Temperature Ratio (TTR) is the ratio of the total temperature of the jet to the ambient temperature. Subscripts "c" and "f" refer to the core and fan streams, respectively. The Mach number is given by $\mathrm{M}$. The single stream experiments were conducted with the core stream at the indicated conditions and the fan stream at conditions equal to that of the flight stream. The dual high subsonic stream experiments were conducted at representative takeoff conditions. The dual stream supersonic fan stream and subsonic core stream experiments were conducted at conditions representative of those that occur for some commercial aircraft at cruise. While free jet Mach numbers $\left(\mathrm{M}_{\mathrm{fj}}\right)$ equal to 0.1 and 0.28 were used in the experiments, only data for $\mathrm{M}_{\mathrm{fj}}=0.1$ are presented here.

\section{Results}

\section{A. Single Low Supersonic Core Stream Experiments}

The acoustic spectra acquired for a single supersonic stream are shown in Fig. 6 for a range of Injection Pressure Ratios (IPR), the ratio of the injected flow stagnation pressure to the ambient pressure. Observation angles greater than $90^{\circ}$ are in the downstream direction relative to the nozzle exit. For supersonic operating conditions, the baseline data are acquired with the air injection nozzles with no injection flow (IPR $=1.0$ ) since the injection nozzles produced slightly different broadband shock noise levels than the baseline nozzle presumably due to slight differences in the core nozzle external contours. As shown in Fig. 6 (a), the broadband shock noise levels decrease as IPR increases. In the peak jet noise direction [see Fig. 6(b)], low frequency broadband levels decrease as IPR increases.

Streamwise velocity contours obtained from PIV experiments for the same conditions as those in Fig. 6 are shown in Fig. 7 for laser light sheet orientation 2. Quasi-periodic shock cells can be seen in the core flows for IPR $=$ 1.0 and 2.0. The shock cells disappear for IPR $=4.0$ which explains the elimination of broadband shock noise in the corresponding spectrum in Figs. 6 (a). Similar results to those shown in Fig. 7 were obtained for laser light-sheet orientation 1.

Turbulent Kinetic Energy (TKE) contour plots obtained from the streamwise PIV experiments for the same conditions as those in Fig. 6 are shown in Figs. 8 and 9 for light sheet orientations 1 and 2, respectively. For the TKE calculations, the out-of-plane component of the velocity fluctuation is assumed equal to that of the transverse component measured in the PIV experiments. For laser light-sheet orientation 1, TKE is higher for the no injection case $(I P R=1.0)$ than for flow with injection (IPR $=2.0$ and 4.0). For light-sheet orientation 2, TKE levels near the end of the potential core decrease with increasing IPR. The lower TKE levels (and corresponding shorter potential core length) for IPR $=2.0$ and 4.0 (relative to IPR $=1.0$ ) are consistent with the corresponding noise reduction levels shown in Fig. 6 (b). Near the nozzle trailing edges in light-sheet orientation 2, the highest turbulent kinetic energy occurs for IPR $=4.0$, a result consistent with the increased high frequency noise (relative to IPR $=1.0$ ) in Fig. 6 (a) for the same IPR.

Streamwise velocity contours and corresponding streamwise vorticity contours with cross-stream velocity vectors obtained from the stereo PIV experiments are shown in Figs. 10 and 11, respectively. The contour levels in Fig. 10 are the same as those in Fig. 7. White regions in the contour plots are regions where few images were used in the ensemble averages due to a lack of correlation from many of the PIV image pairs as a result of flare from nozzle surfaces. The vorticity contours are an exploded view as shown in Fig. 11. Enlarged pairs of velocity vectors along with red arrows indicating regions of injected flow are shown in the first contour plot of Fig. 11 for clarity. The fluidic injectors create streamwise counter-rotating vortex pairs (shown as high vorticity levels in Fig. 11) that draw ambient flow into the core flow creating "lobes" in the core stre am flow [see Figs. 10 (b) and (c)] and enhancing the mixing between the core stream and ambient flow. Increasing IPR increases peak vorticity levels and jet mixing within the first three diameters downstream of the nozzle exit. 


\section{B. Dual High Subsonic Stream Experiments}

The acoustic spectra acquired at the dual high subsonic stream conditions (representative takeoff conditions) in Table 1 are shown in Fig. 12 and Fig. 13 for the steep and shallow injectors, respectively. For subsonic jet flows, the baseline data are taken with the baseline nozzle. For steep injectors, increasing IPR increases high frequency noise relative to the baseline nozzle at a $90^{\circ}$ observation angle [see Fig. 12 (a)]. In the peak jet noise direction, the introduction of air injection decreases low frequency noise. The acoustic spectra produced by the baseline nozzle and the shallow injectors with IPR $=3.2$ are similar (see Fig.13) although the shallow injectors produce slight low frequency noise reduction in the peak jet noise direction relative to the baseline nozzle.

Streamwise velocity contours obtained from the streamwise PIV experiments for the baseline, steep fluidic injection, and shallow fluidic injection nozzles are shown in Fig. 14 for the same jet conditions as those used in Figs. 12 and 13. Data for the baseline nozzle were only obtained for laser light-sheet orientation 2 since this orientation captured two areas of flow extremes: (1) downstream of the pylon where turbulence levels usually peak and (2) on the side of the jet opposite to the pylon where the pylon effects on the jet are a minimum. Data for the shallow fluidic injection nozzle and laser light-sheet orientation 2 were not acquired due to testing time constraints. For the steep fluidic injection nozzle, the length of the primary potential core decreases as the injection pressure ratio increases indicating increased mixing with increased IPR. For the shallow fluidic injection nozzle, the primary potential core length is shorter than that for the baseline nozzle but longer than that for the steep fluidic injection nozzle operated at the same IPR. The larger noise reductions for the steep injection nozzle than for the shallow injection nozzle relative to the baseline nozzle [see Figs. 13 (b) and 14 (b)] are most likely associated with the greater mixing rate of the steep injectors than the shallow injectors.

Turbulent kinetic energy contour plots for the same conditions as those in Fig. 14 are shown in Fig. 15. Since data for the shallow injectors were only obtained for light-sheet orientation 1, results for both light-sheet orientations have been included for the steep fluidic injector to allow for comparisons between the two types of injectors. The highest TKE levels occur for the baseline nozzle downstream of the pylon. The peak TKE level for the steep fluidic injection nozzle is higher than that for the shallow fluidic injection nozzle at the same IPR using the same light-sheet orientation (orientation 1).

Streamwise velocity contours and corresponding streamwise vorticity contours with cross-stream velocity vectors obtained from the stereo PIV experiments are shown in Figs. 16 and 17, respectively. The asymmetry in the lower center region of the baseline nozzle core stream is the result of a bifurcator in the fan stream upstream of the nozzle trailing edge. As in the case of the single stream experiments, the fluidic injectors create streamwise counterrotating vortex pairs that draw surrounding fluid (fan stream flow) into the core flow and enhance mixing between the two streams. The effects of the pylon (and possibly the upstream fan-stream bifurcator) may impact vortex development with downstream distance and result in the lack of vortex pair strength symmetry. The influence of the vortex pairs on the core and fan stream flows appears to extend much further downstream for the slotted injectors used in these experiments than for microjet injectors used by Refs. 2 and 3. Although not evident in Fig. 18 due to selecting a maximum vorticity contour level well below the maximum vorticity level near the nozzle exit (for clarity at cross-stream locations where vorticity levels are low), the peak vorticity levels produced by the steep injection nozzle are higher for IPR $=3.2$ than for IPR $=2.4$ within the first three core jet diameters resulting in greater mixing for IPR $=3.2$ than for IPR $=2.4$ jet. However, vorticity levels decay more rapidly for IPR $=3.2$ than for IPR $=2.4$ at axial locations greater than three jet diameters. The peak vorticity levels for the steep and shallow injectors at the same IPR are very similar for the first three core jet diameters although the spatial extent of vorticity is slightly different for the two flows.

\section{Low Supersonic Fan Stream with Subsonic Core Stream Experiments}

The acoustic spectra for dual-stream jets with supersonic fan streams and subsonic core streams at a free jet Mach number equal to 0.10 are shown in Fig. 18. The steep fluidic injection nozzle was used for the core flow and IPR $=$ 1.0 was used for the baseline data. The introduction of injected flow reduces broadband shock noise but has little effect on mixing noise. Experiments conducted at higher nozzle pressure ratios $\left(\mathrm{NPR}_{\mathrm{f}}=2.36\right.$ and $\left.\mathrm{NPR}_{\mathrm{c}}=1.82\right)$ showed that fluidic injection had no broadband shock or mixing noise reduction benefits relative to the no-injection case.

Streamwise velocity contours obtained at the same jet conditions as those in Fig. 18 are shown in Fig. 19 for laser light-sheet orientation 2. Shock cells can be seen in the fan stream of both jet plumes (IPR =1.0 and 3.0) on the side of the jet opposite to the pylon although higher levels of injection (IPR $=3.0)$ reduce the axial extent of the shock cells. Similar results were obtained for laser light-sheet orientation 1. The inability to eliminate shock cells with 
fluidic injection at least partially explains the inability to eliminate broadband shock noise with fluidic injection [see 18 (a)].

Streamwise velocity contours and corresponding streamwise vorticity contours with cross-stream velocity vectors obtained from the stereo PIV experiments are shown in Figs. 20 and 21, respectively. The impact of the injection passages can be seen in the fan stream flow for the no injection case (IPR $=1.0)$. For IPR $=3.0$, the core stream "lobes" associated with counter rotating vortex pairs are observed but produce limited o $r$ no mixing between the fan and free-jet streams (possibly explaining the lack of mixing noise reduction in Fig. 18 for IPR $=3.0$ relative to IPR $=$ 1.0). The distortion of the fan-core shear layer may account for the decrease in the shock train length for IPR $=3.0$ relative to IPR $=1.0$. The corresponding vorticity plots in Fig. 21 show that the injection passages in the no injection case (IPR $=1.0)$ produce vorticity of the opposite sign to that of the injected flow with IPR $=3.0$. For the supersonic fan stream and subsonic core stream, the vorticity associated with the injected flow has little effect on the fan stream which most likely explains the lack of noise reduction observed in Fig. 18 for IPR $=3.0$ (relative to the no injection case).

\section{Discussion and Conclusions}

Experiments conducted with a fluidic nozzle for a single, supersonic jet show the potential for fluidic injection to reduce broadband shock noise and low frequency mixing noise. Reductions in peak TKE near the end of the potential core and enhanced mixing are also achieved with the introduction of fluidic injection.

The introduction of fluidic injection in the core stream of a dual stream jet at a representative commercial takeoff condition results in low frequency noise reduction in the peak jet noise direction with slight increases in high frequency noise at $90^{\circ}$. Fluidic injection reduces (relative to the baseline nozzle) TKE levels downstream of the pylon near the end of the primary potential core. The influence of counter-rotating vortex pairs produced by the injected flow on the core and fan streams appears to extend further downstream than that produced by microjet injectors [see Refs. 2 and 3].

The introduction of fluidic injection on the core stream of a dual stream jet with a supersonic fan stream and a subsonic core stream can reduce broadband shock noise but has no mixing noise benefit. Particle image velocimetry studies show that, for this flow regime, fluidic injection has little impact on the fan stream.

\section{References}

\footnotetext{
${ }^{1}$ Henderson, B. "Fifty years of fluidic injection for jet noise reduction," International J. Aeroacoustics, Vol. 9, pp. 91 - 122, 2010.

${ }^{2}$ Alkisler, M. B., Krothapalli, A., and Butler, G. W. "The effect of streamwise vortices on the aeroacoustics of a Mach 0.9 jet,” J. Fluid Mech. 578, pp. 139 - 169, 2007.

${ }^{3}$ Alkislar, M. B. "Aeroacoustics of a Mach 0.9 jet with chevron-microjet combination," AIAA-2008-3041, 2008.

${ }^{4}$ Henderson, B., Kinzie, K., Whitmire, J., and Abeysinghe, A. "Aeroacoustic improvements of fluidic chevron nozzles," AIAA-2006-2706, 2006.

${ }^{5}$ Harrison, S., Gutmark, E., and Martens, S. "Jet noise reduction by fluidic injection on a separate flow exhaust system," AIAA-2007-439, 2007.

${ }^{6}$ Margason, R. "Fifty years of jet in cross-flow research," AGARD Meeting on Computational and Experimental Assessment of Jets in Cross Flow, April 1993, N94-28004, 1993.

${ }^{7}$ Arakeri, V. H., Krothapalli, A., Siddavaram, V., Alkislar, M. B., and Lourenco, L. M. "On the use of microjets to suppress turbulence in a Mach 0.9 axisymmetric jet," J. Fluid Mech. 490, 75-98, 2003.

${ }^{8}$ Laurendeau, E., Bonnet, J. P., Jordan, P., and Delville, J. "Impact of fluidic chevrons on the turbulence structure of a subsonic jet, AIAA-2006-3510, 2006.

${ }^{9}$ Callender, B., Gutmark, E., and Martens, S. "A comprehensive study of fluidic injection technology for jet noise reduction," AIAA-2007-3608, 2007.

${ }^{10}$ Alkislar, M. B., Krothapalli, A., Lourenco, L. M. and Butler, G. W. "The effect of streamwise vorticity on the aeroacoustics of Mach 0.9 axisymmetric jet," AIAA-2005-3045, 2005.

${ }^{11}$ Chauvet, N., Deck, S., and Jacquin, L. "Zonal detached eddy simulation of a controlled propulsive jet,” AIAA J. 45 [10], 2458-2473, 2007.

${ }^{12}$ Kinzie, K., Henderson, B., Whitmire, J., Abeysinghe, A. (2004). "Fluidic chevrons for jet noise reduction," ACTIVE 04, Williamsburg, Virginia, September 20 - 22, 2004.

${ }^{13}$ Henderson, B., Kinzie, K., Whitmire, J., and Abeysinghe, A. "Aeroacoustic improvements of fluidic chevron nozzles," AIAA-2006-2706, 2006.

${ }^{14}$ Henderson, B. and Norum, T. "Impact of fluidic chevrons on supersonic jet noise," AIAA-2007-3595, 2007.

${ }^{15}$ Amiet, R. K., "Correction of open jet wind tunnel measurements for shear layer refraction," AIAA-77-54, 1977.

${ }^{16}$ ANSI S1.26-1995 (R2004), "Method for calculation of absorption of sound by the atmosphere,".

${ }^{17}$ Soeder, R., Wnuk, S., and Loew, R. "Aero -Acoustic Propulsion Laboratory Nozzle Acoustic Test Rig User Manual," NASA/TM-2006-212939, 2006.
} 


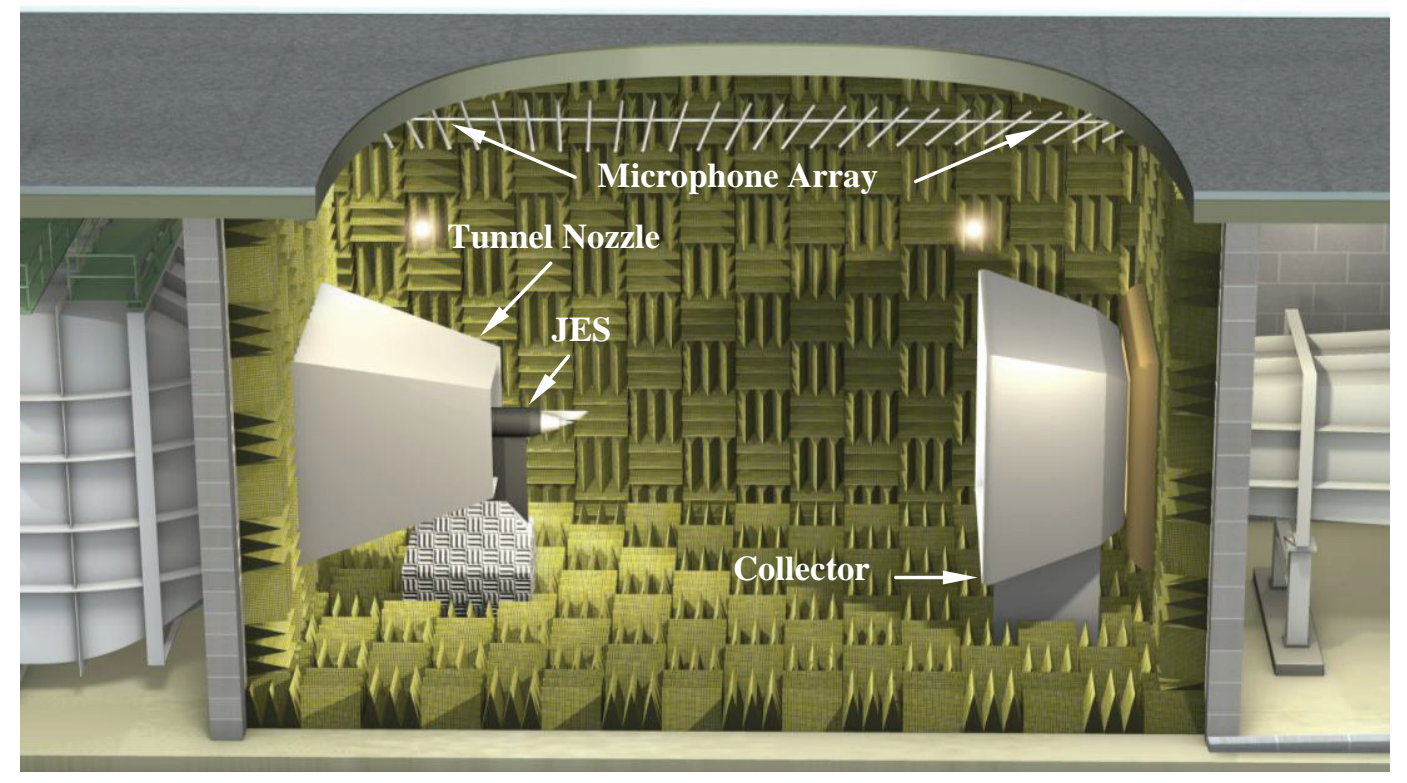

Figure 1. A schematic of the Low Speed Aeroacoustics Wind Tunnel (LSAWT) and the Jet Engine Simulator (JES).

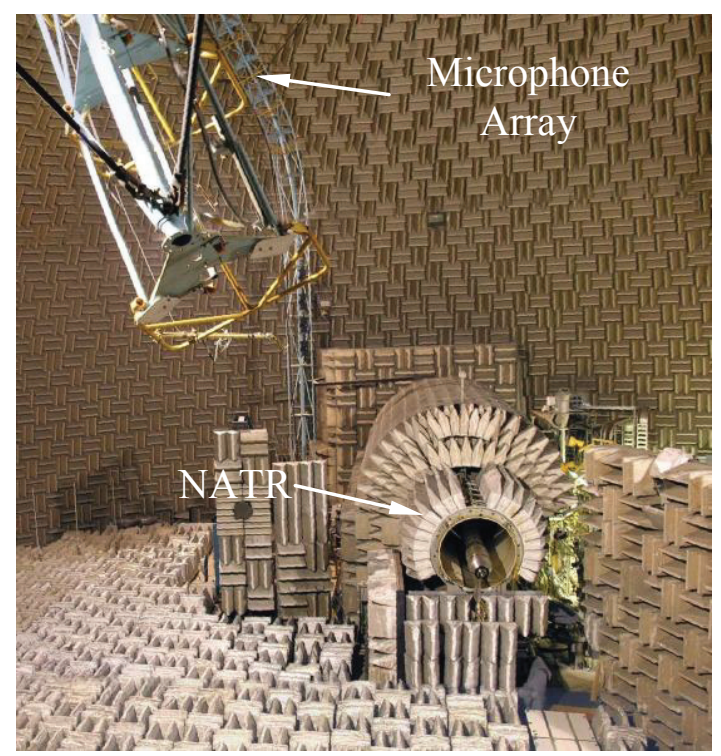

Figure 2. A photograph of the AeroAcoustic Propulsion Laboratory (AAPL) showing the Nozzle Acoustic Test Rig (NATR). 


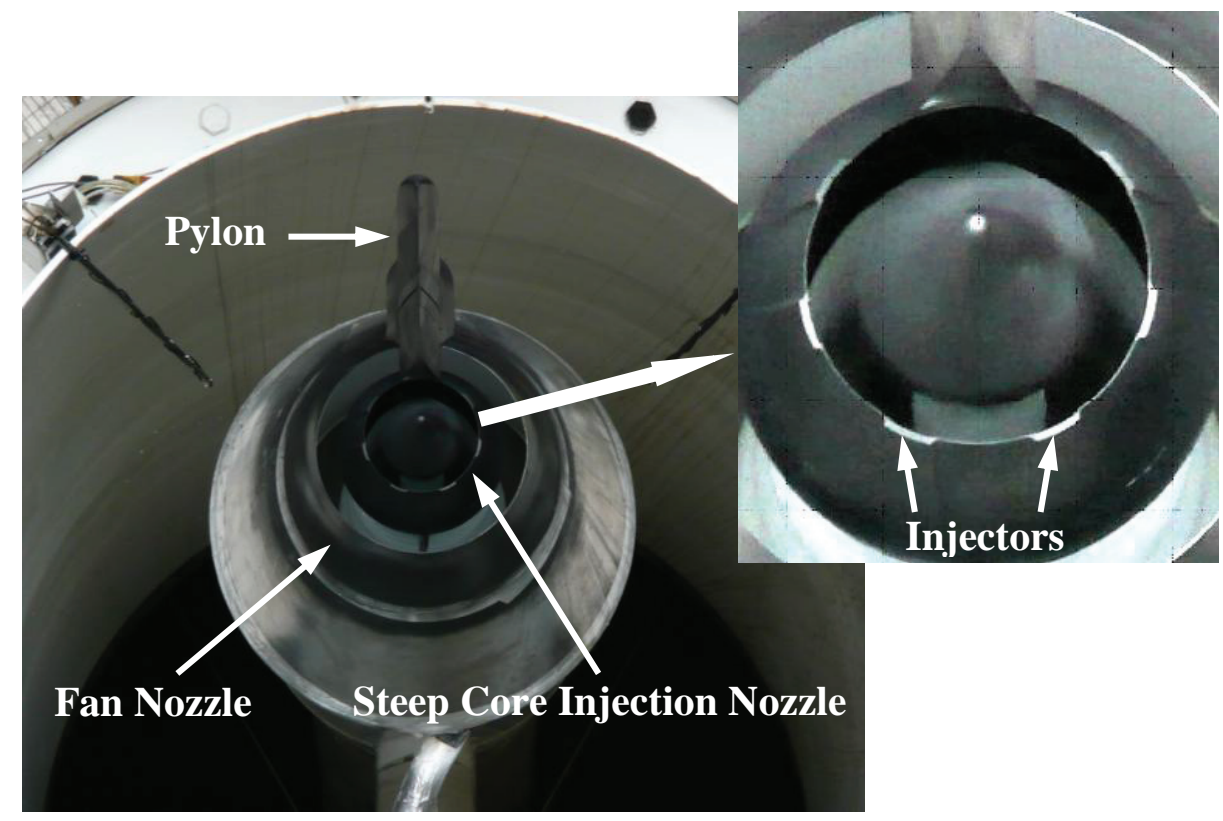

Figure 3. The air injection nozzle system used in acoustic and PIV experiments.

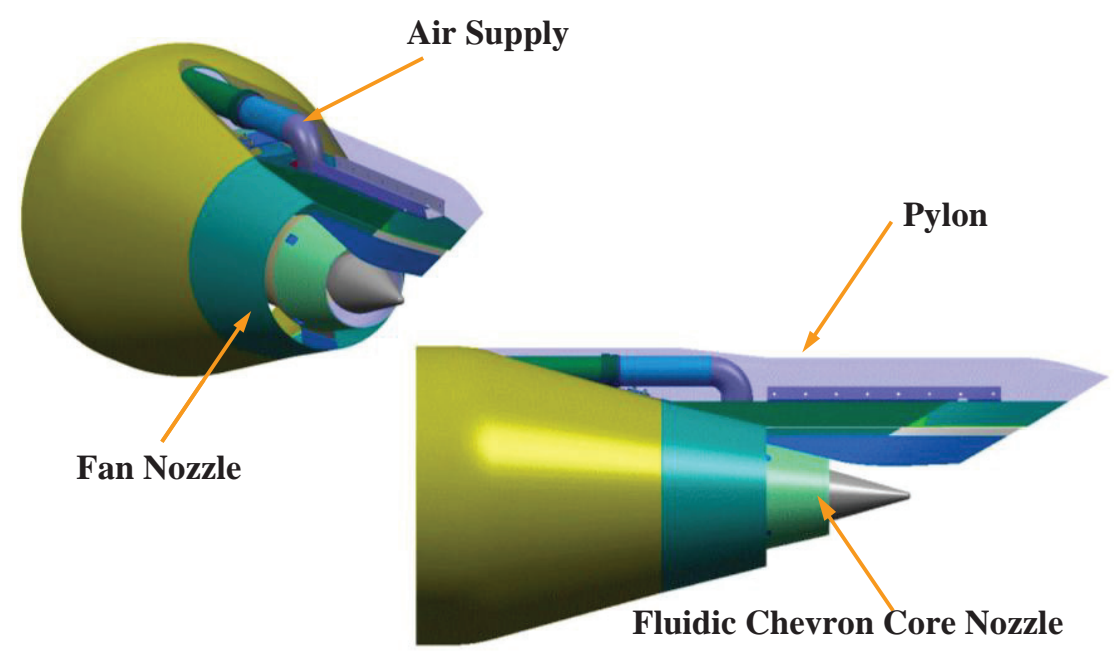

Figure 4. A schematic of the air delivery system for the air injection nozzles.

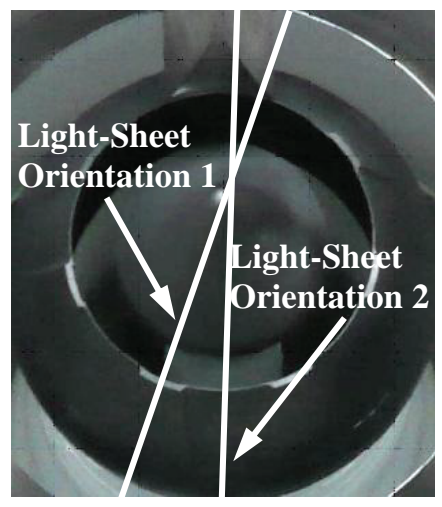

Table 1 Experimental Operating Conditions

\begin{tabular}{|c|c|c|c|c|}
\hline $\mathbf{N P R}_{\mathbf{c}}$ & $\mathbf{T T R}_{\mathbf{c}}$ & $\mathbf{N P R}_{\mathbf{f}}$ & $\mathbf{T T R}_{\mathbf{f}}$ & Experiment \\
\hline 2.18 & 1.06 & 1.01 & 1.00 & Single Low Supersonic Core Stream \\
\hline 1.56 & 2.66 & 1.75 & 1.16 & Dual High Subsonic Streams \\
\hline 1.61 & 2.13 & 2.24 & 1.05 & $\begin{array}{r}\text { Low Supersonic Fan Stream with } \\
\text { Subsonic Core Stream }\end{array}$ \\
\hline
\end{tabular}

Figure 5. The laser lightsheet orientations used in the streamwise PIV experiments. 


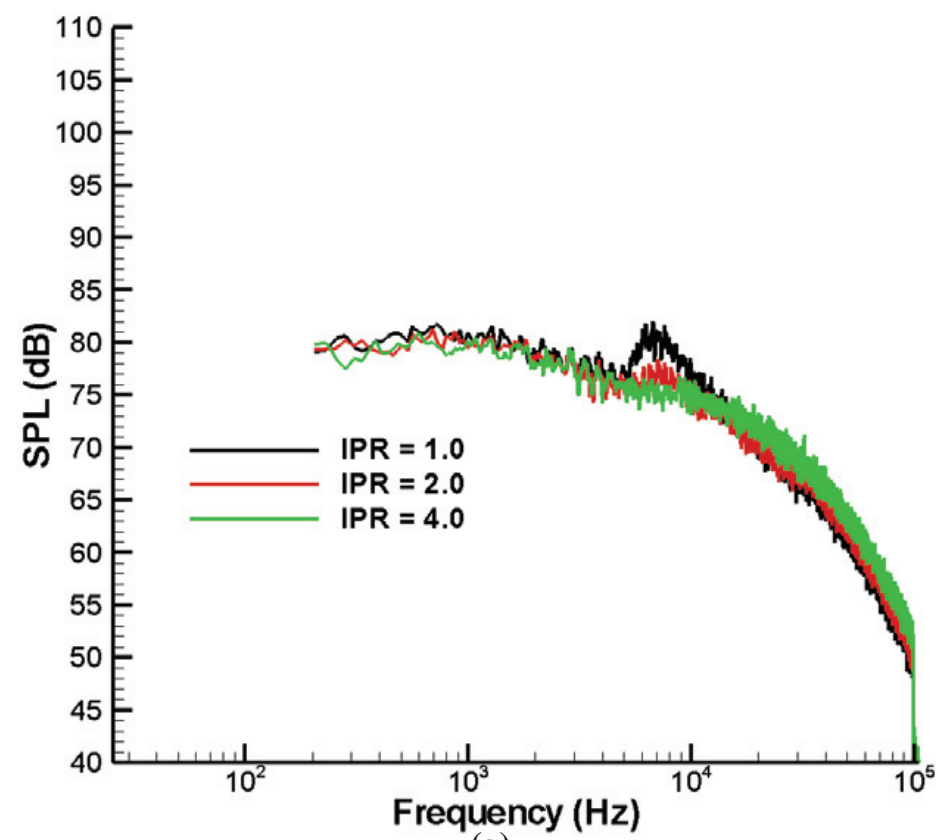

(a)

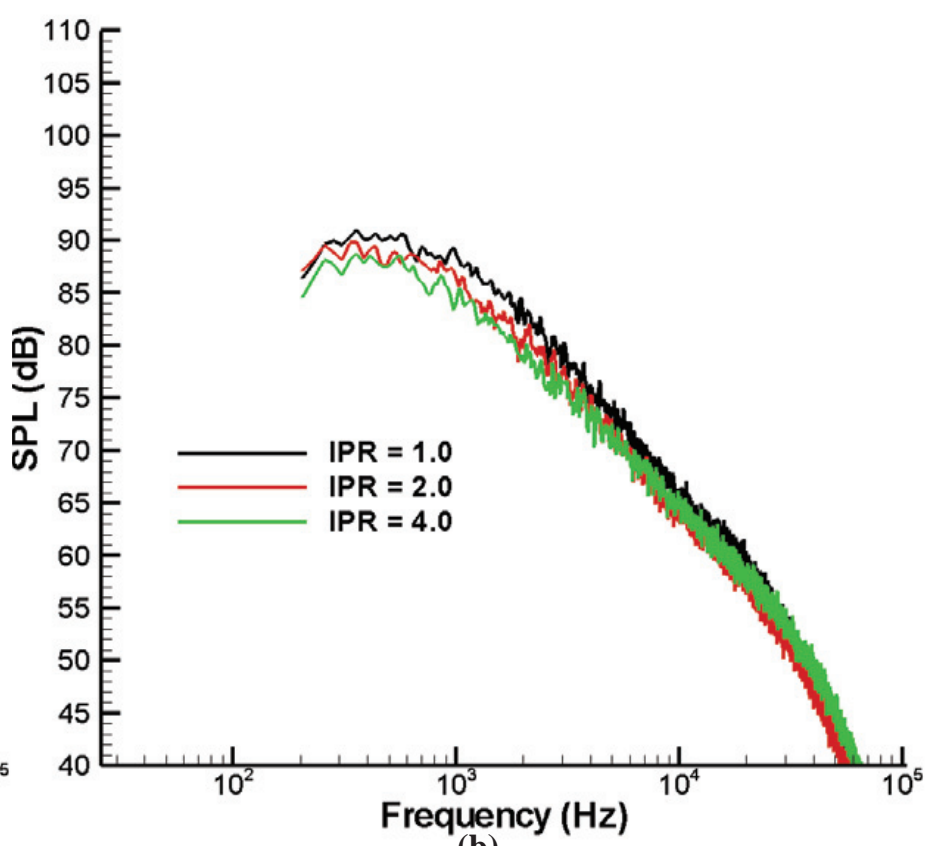

(b)

Figure 6. Narrowband spectra acquired for a single stream supersonic jet using the steep fluidic injection core nozzle for observation angles equal to (a) $90^{\circ}$ and (b) $150^{\circ}$.

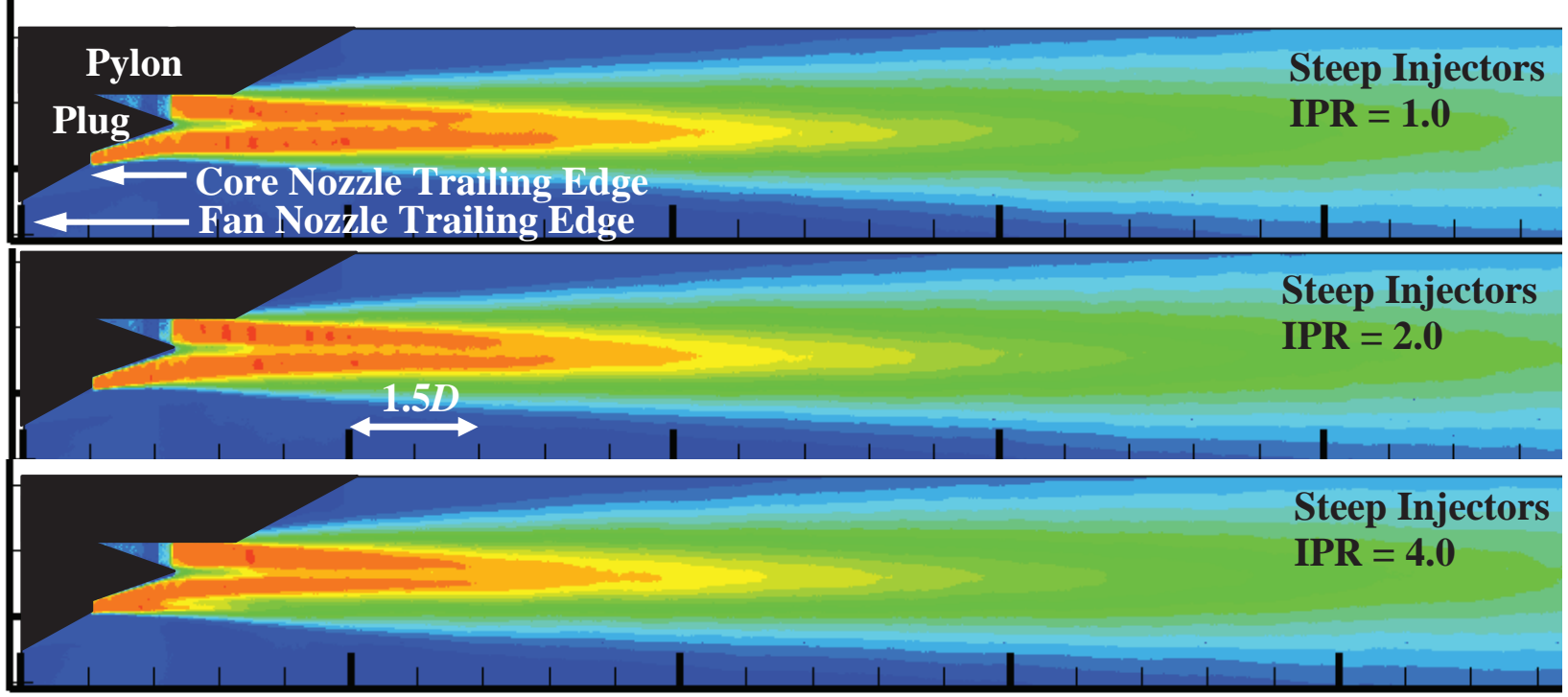

Figure 7. Streamwise velocity contours obtained from the streamwise PIV experiments with laser light-sheet 


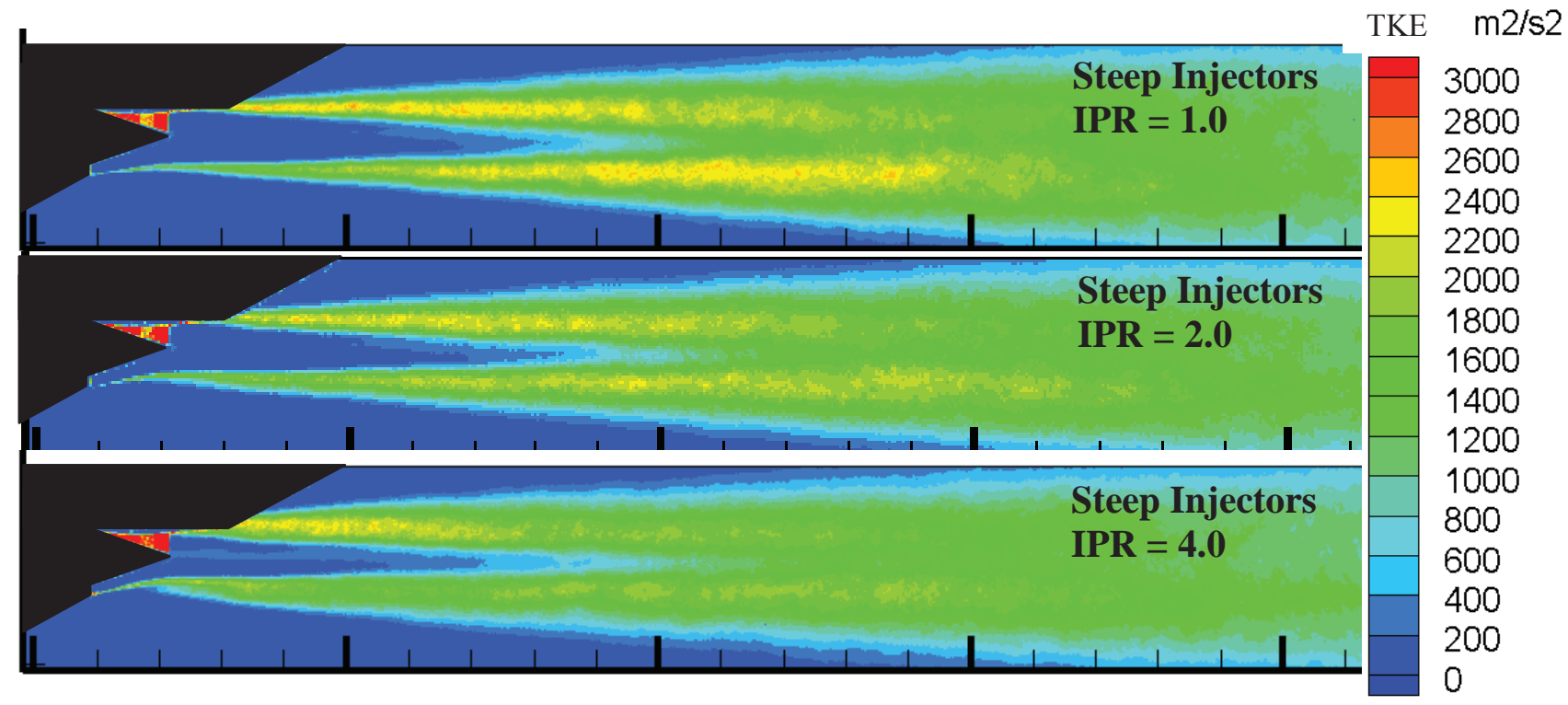

Figure 8. Turbulent kinetic energy contours obtained for the streamwise PIV experiments with laser light-sheet orientation 1 for the conditions in Fig. 6.

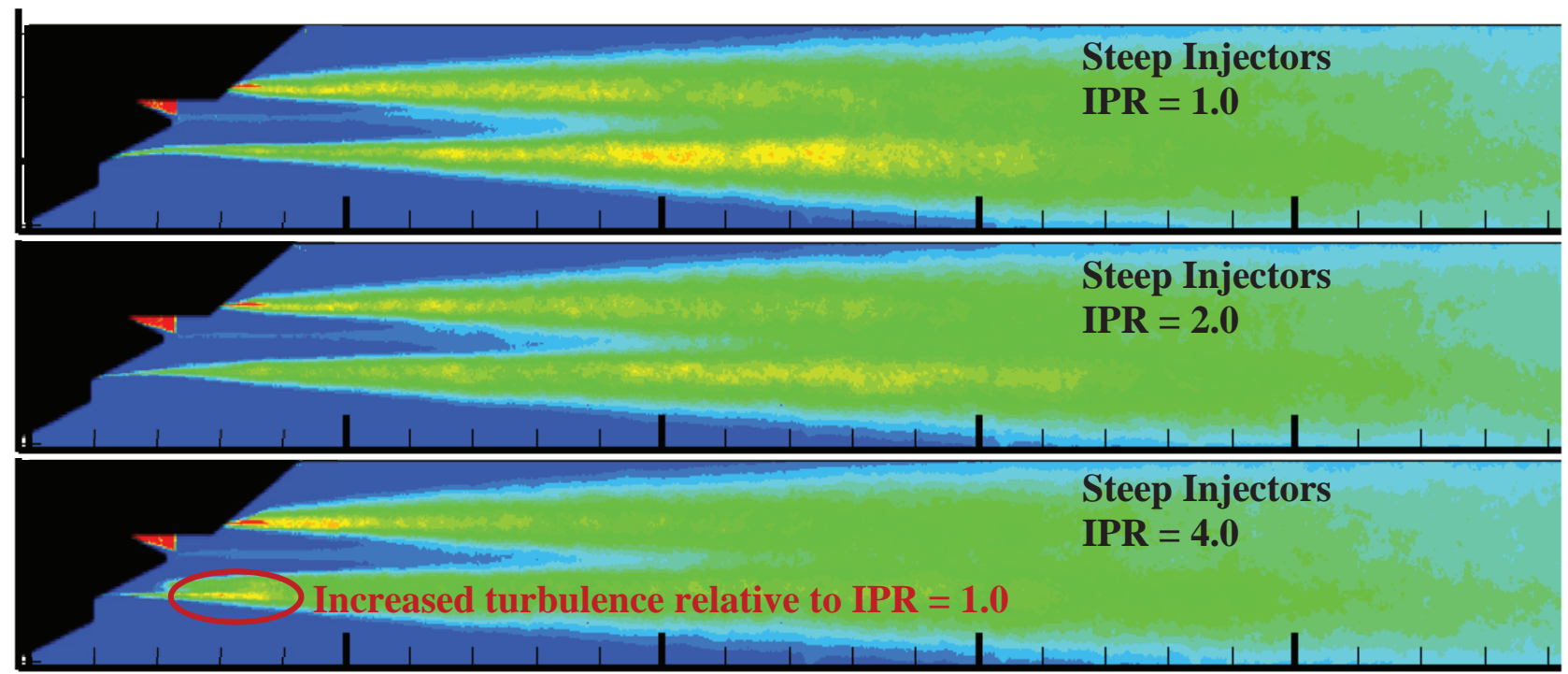

Figure 9. Turbulent kinetic energy contours for the conditions in Fig. 6 obtained for the streamwise PIV experiments with laser light-sheet orientation 2. The legend is the same as that used in Fig. 8. 

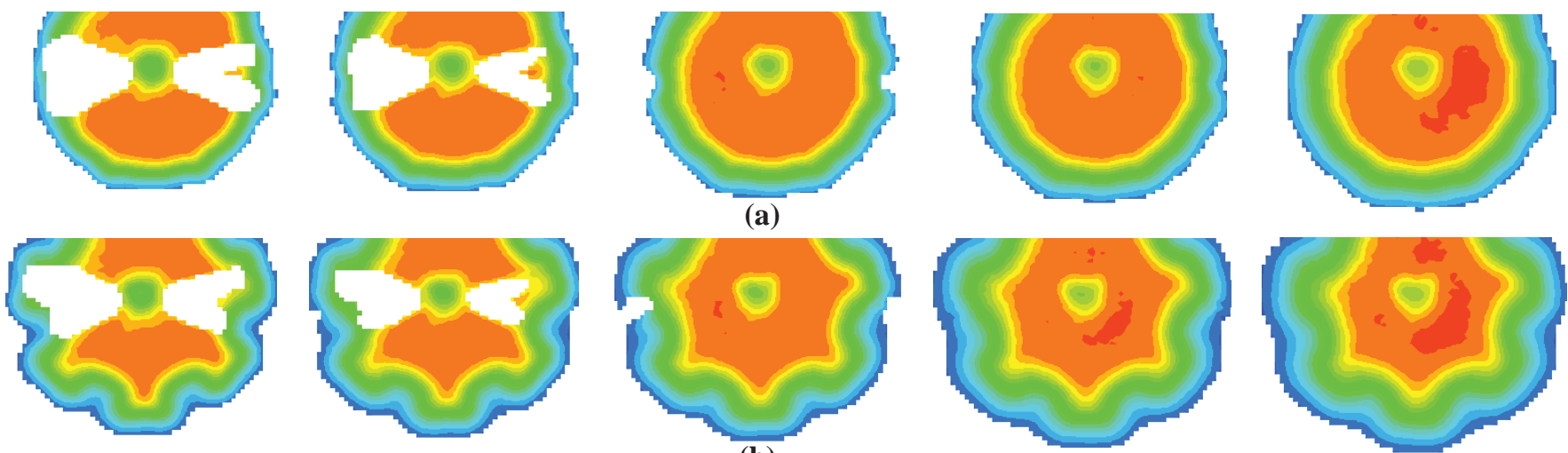

(b)
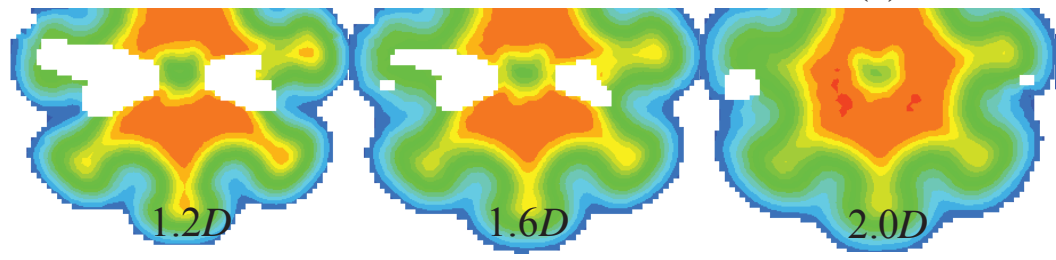

(c)
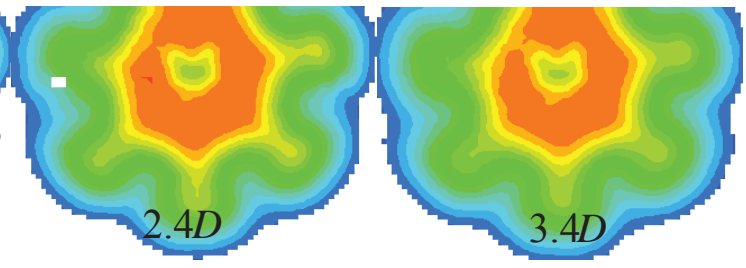

Figure 10. Streamwise velocity contours obtained in the cross-stream planes indicated in the plots for (a) the steep injection nozzle with IPR $=1.0$, (b) the steep injection nozzle with IPR $=2.0$, and (c) the steep injection nozzle with IPR $=4.0$. The legend is the same as that used in Fig. 7

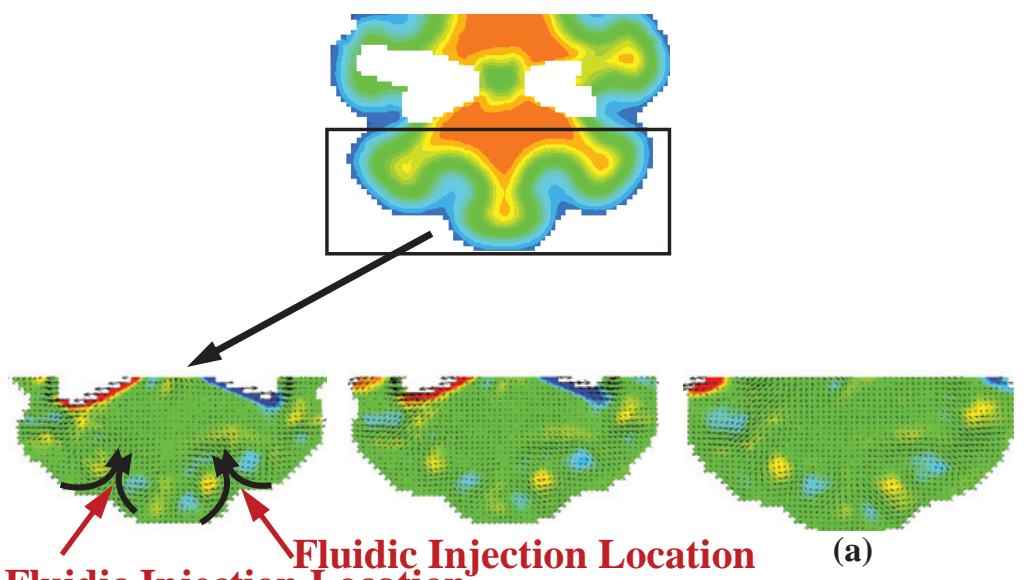

Fluidic Injection Location
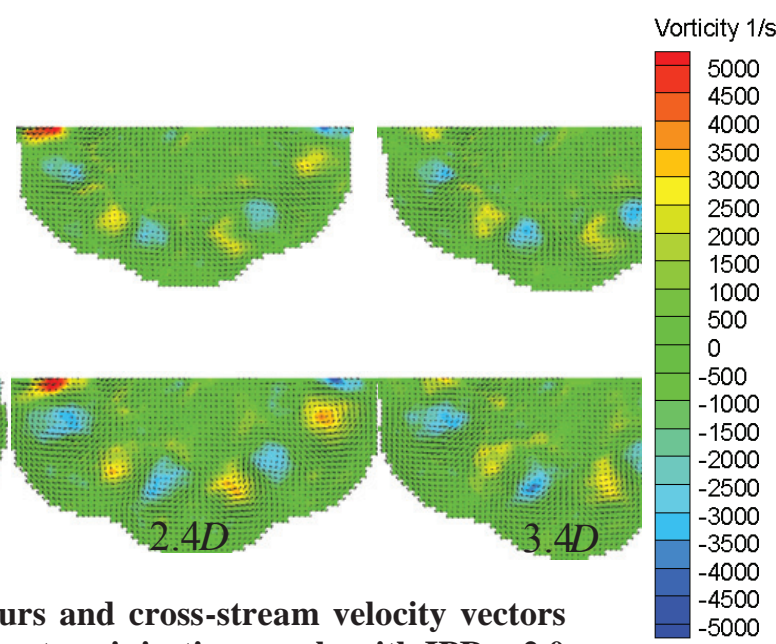

Figure 11. An exploded view of the streamwise vorticity contours and cross-stream velocity vectors obtained in the cross-stream planes indicated in the plots for (a) the steep injection nozzle with IPR $=2.0$ and (b) the steep injection nozzle with IPR $=4.0$. 


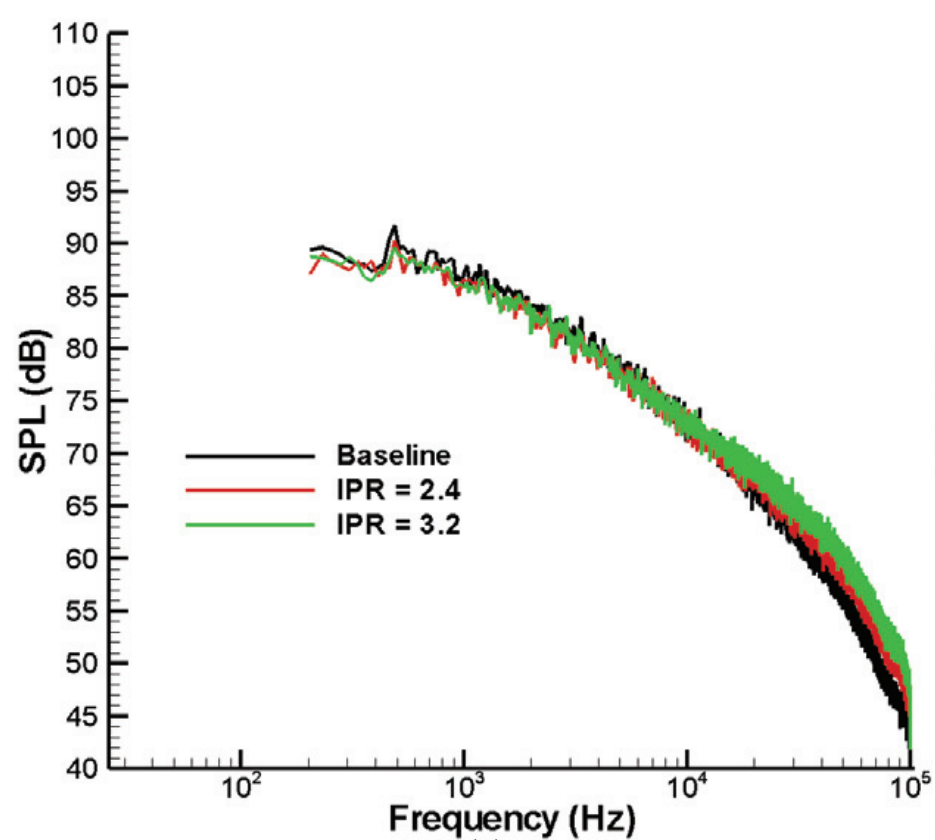

(a)

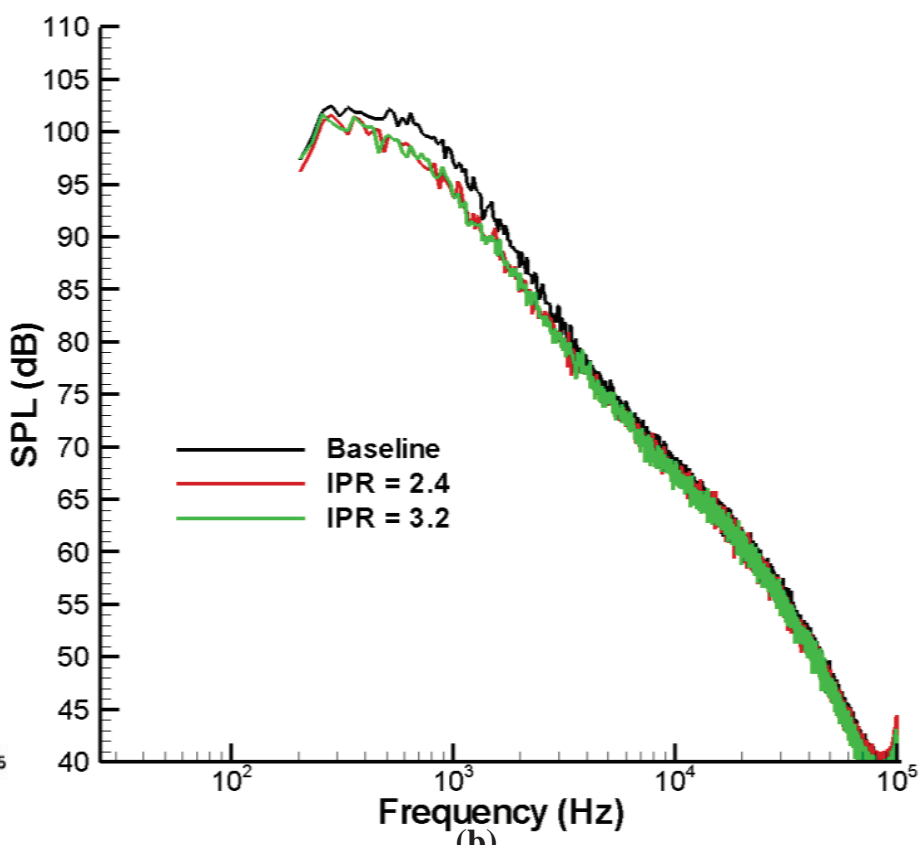

(b)

Figure 12. Narrowband spectra acquired at a representative takeoff condition using the baseline and steep fluidic injection nozzles for observation angles equal to (a) $90^{\circ}$ and (b) $150^{\circ}$.

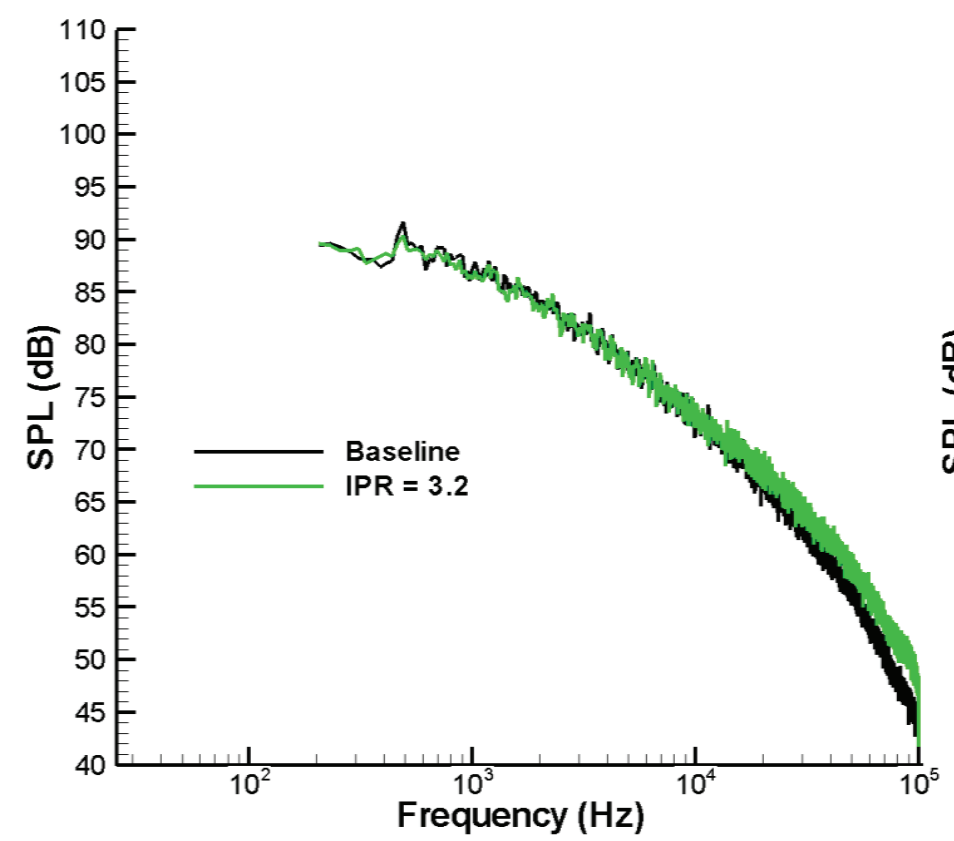

(a)

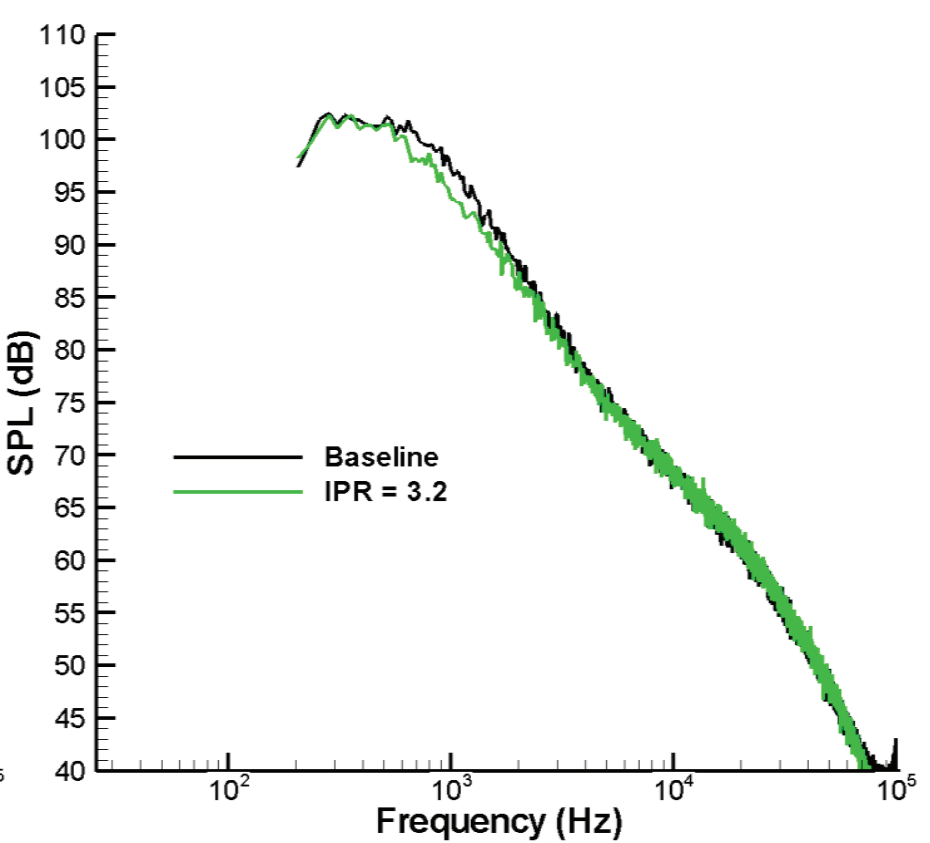

(b)

Figure 13. Narrowband spectra acquired at a representative takeoff condition using the baseline and shallow fluidic injection nozzles for observation angles equal to (a) $90^{\circ}$ and (b) $150^{\circ}$. 


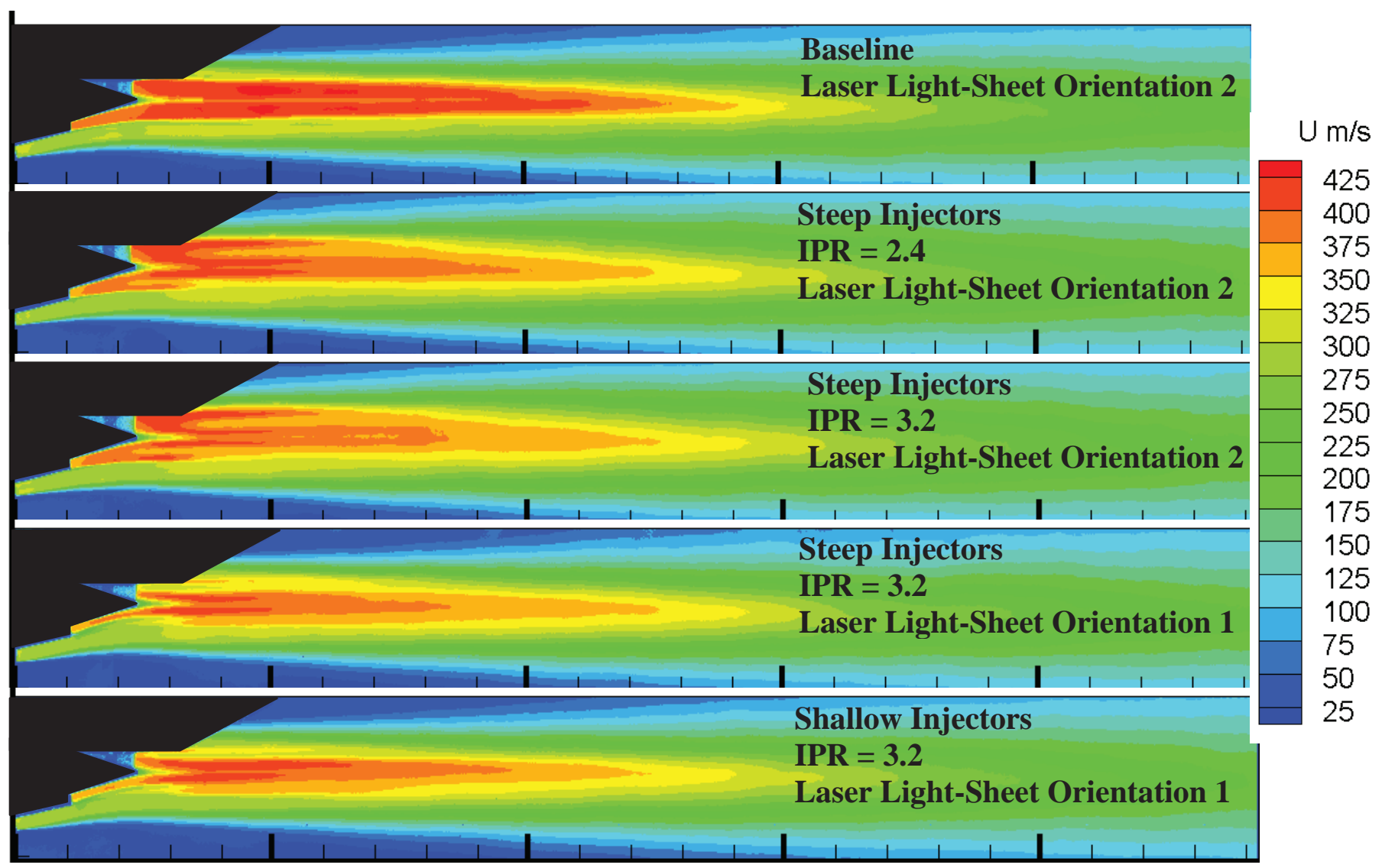

Figure 14. Streamwise velocity contours obtained from the streamwise PIV experiments for the jet conditions in Figs. 12 and 13. 


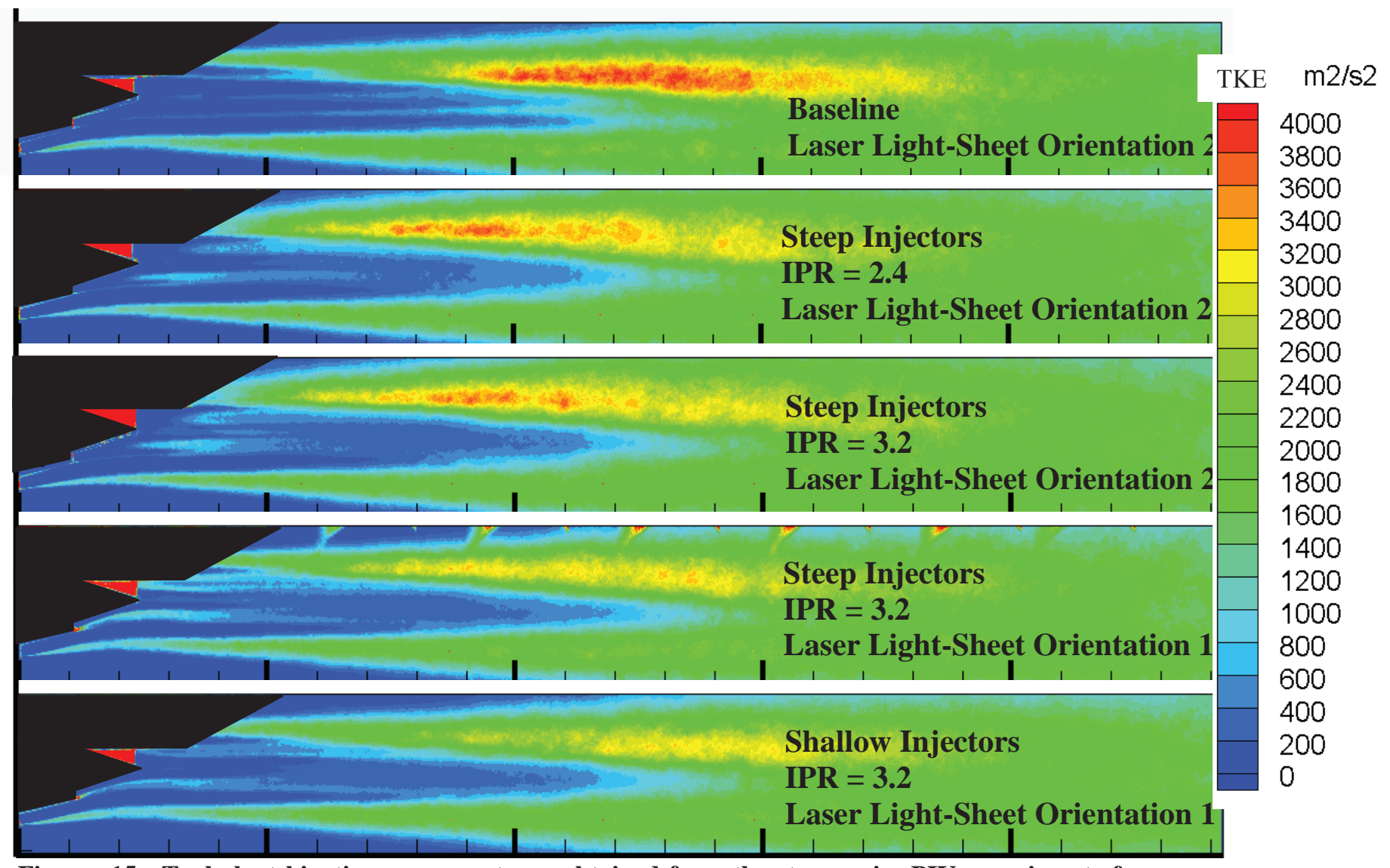

Figure 15. Turbulent kinetic energy contours obtained from the streamwise PIV experiments for the jet conditions in Figs. 12 and 13. 

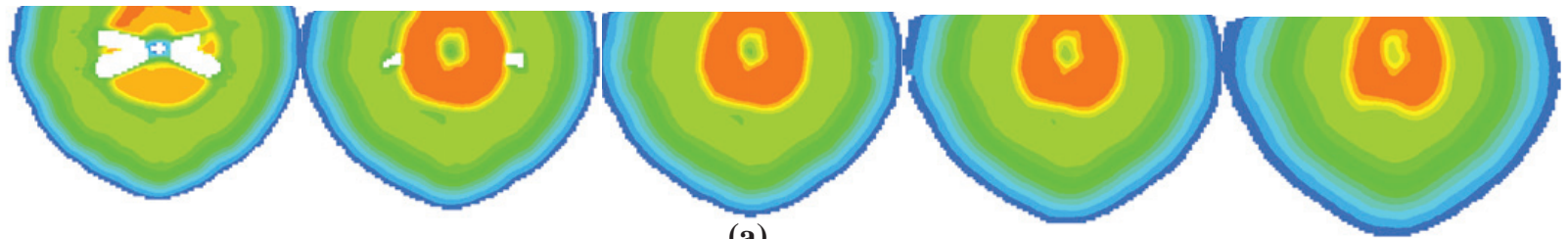

(a)
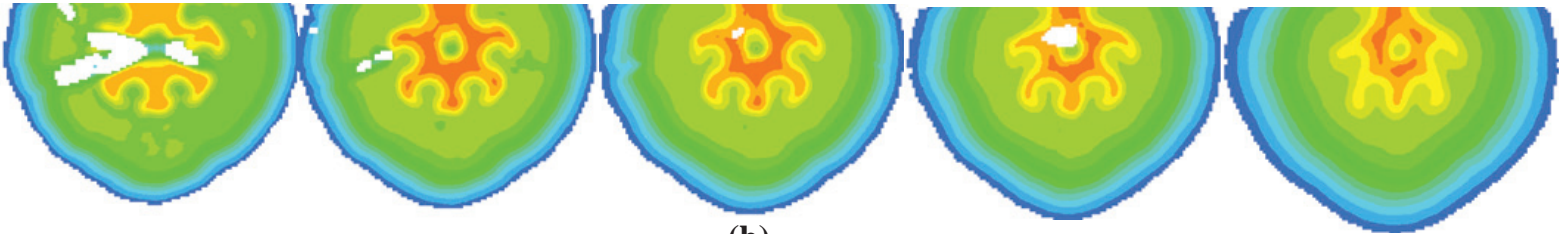

(b)
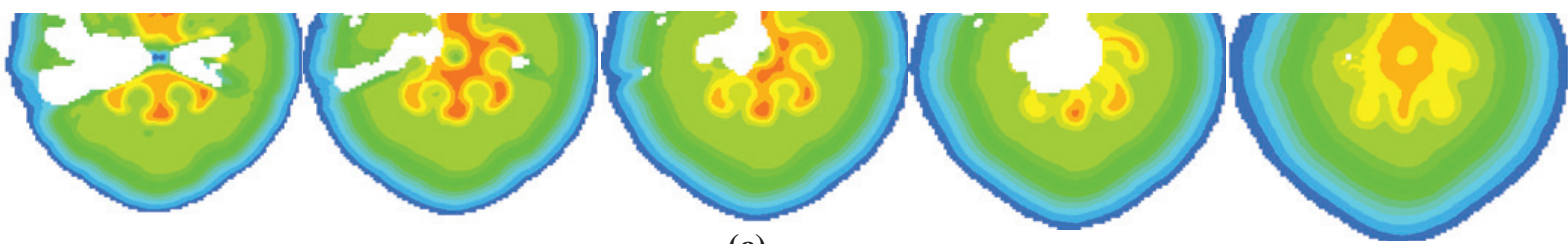

(c)
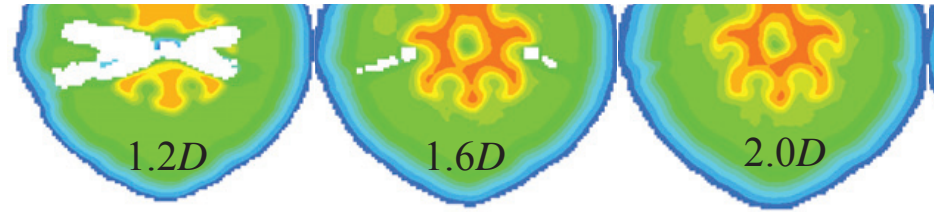

(d)
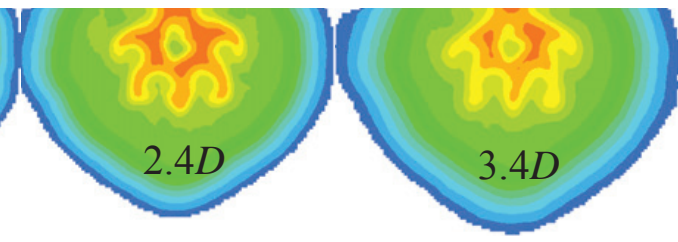

Figure 16. Streamwise velocity contours obtained in the cross-stream planes indicated in the plots at the jet conditions in Figs. 12 and 13 for (a) the baseline nozzle (b) the steep injection nozzle with IPR = 2.4, (c) the steep injection nozzle with IPR $=3.2$, and $(d)$ the shallow injection nozzle with IPR $=3.2$. The legend is the same as that used in Fig. 14
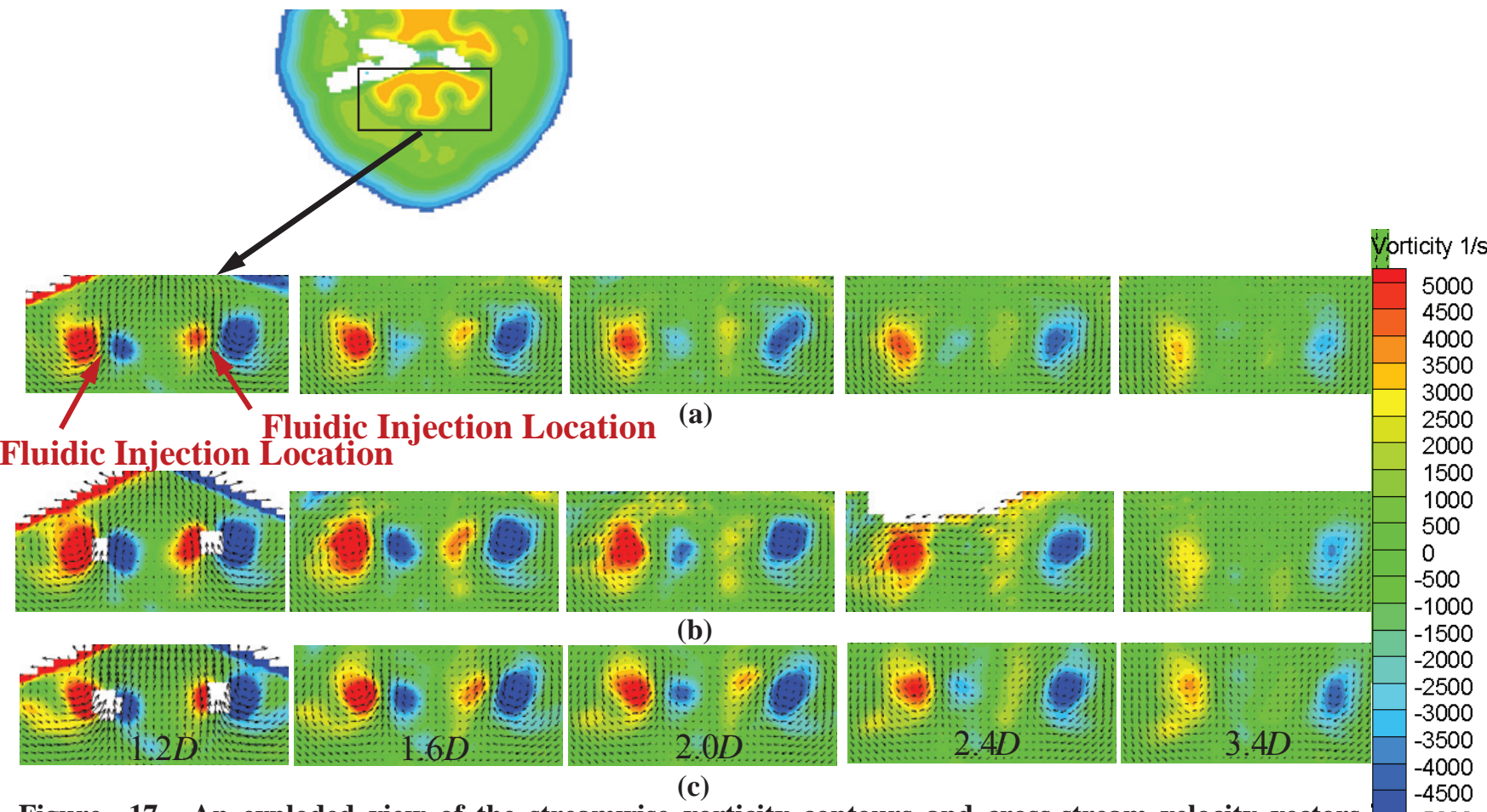

(b)
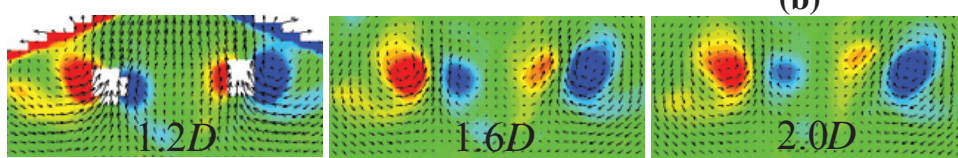

(c)

Figure 17. An exploded view of the streamwise vorticity contours and cross-stream velocity vectors obtained in the cross-stream planes indicated in the plots for the jet conditions in Figs. 12 and 13 for (a) the steep injection nozzle with IPR $=2.4$, (b) the steep injection nozzle with IPR $=3.2$, and (c) the shallow injection nozzle with IPR $=3.2$. 

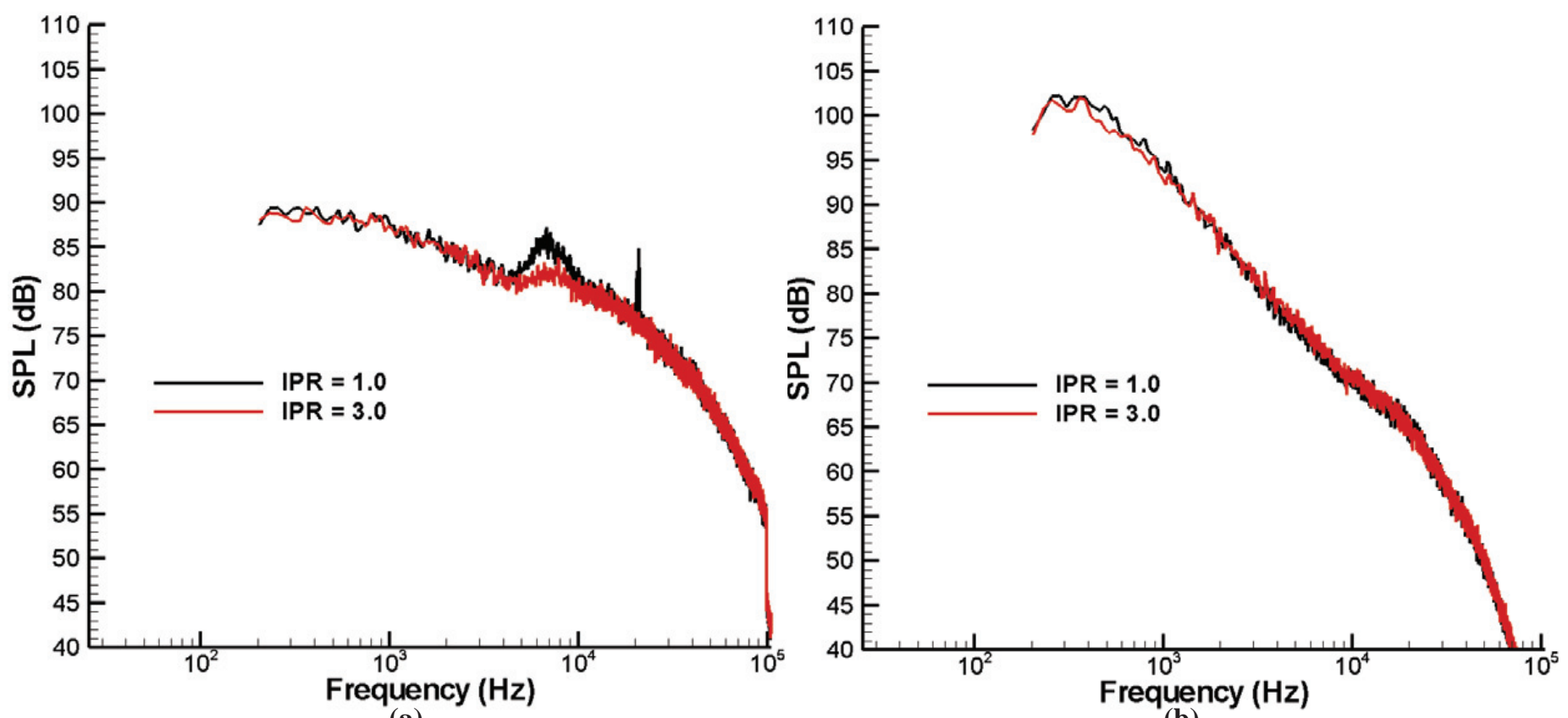

(a)

(b)

Figure 18. Narrowband spectra acquired for a dual stream jet with a supersonic fan stream and a subsonic core stream using the steep fluidic injection nozzle for observation angles equal to (a) $90^{\circ}$ and (b) $150^{\circ}$.

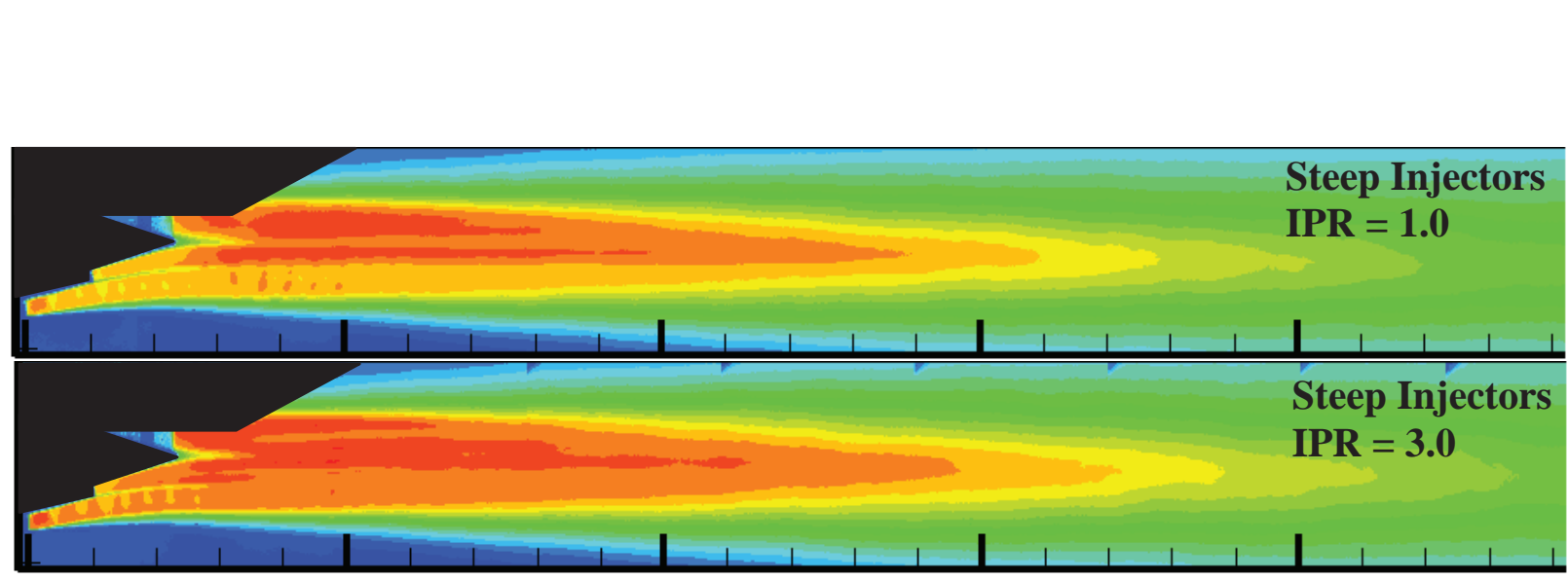

$\mathrm{Um} / \mathrm{s}$

400

375

350

325

300

275

250

225

200

175

150

125

Figure 19. Streamwise velocity contours obtained from the streamwise PIV experiments for the jet conditions in Fig. 18 and laser light-sheet orientation 2. 

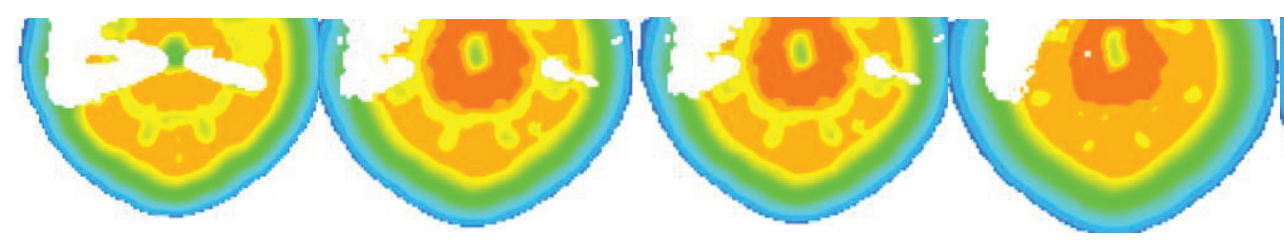

(a)
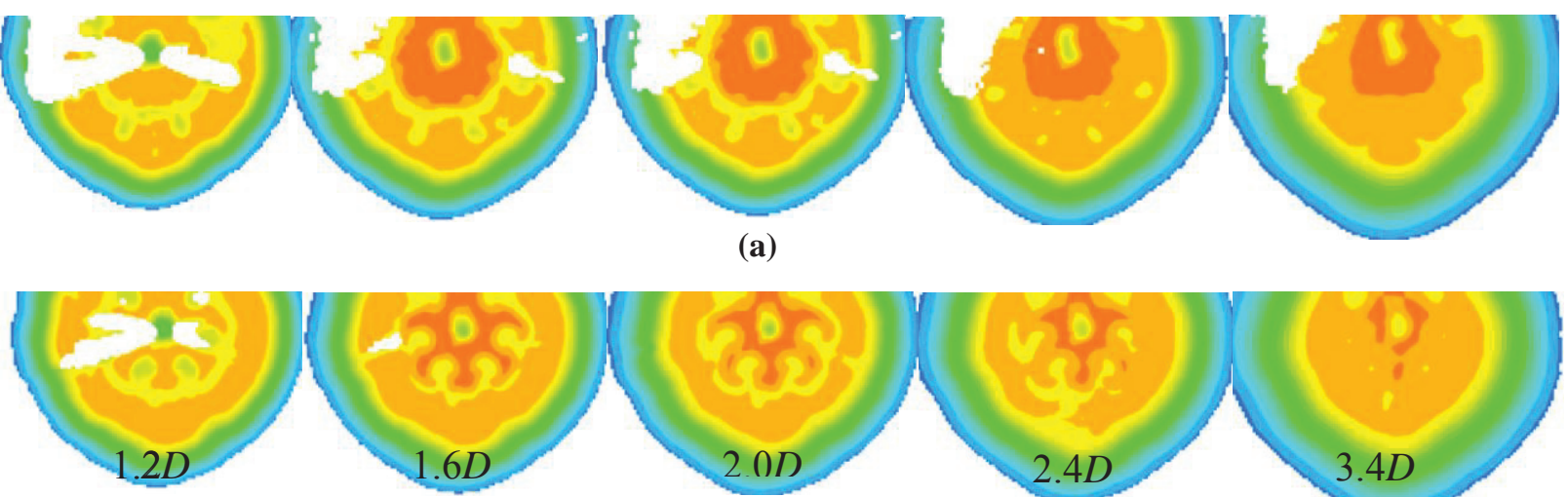

(b)

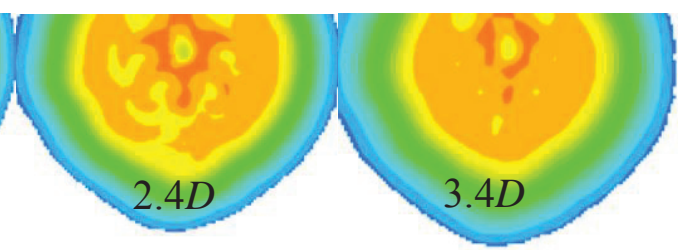

Figure 20. Streamwise velocity contours obtained in the cross-stream planes indicated in the plots at the jet conditions in Fig. 18 for the steep injection nozzle with (a) IPR $=1.0$ and (b) IPR $=3.0$. The legend is the same as that used in Fig. 19

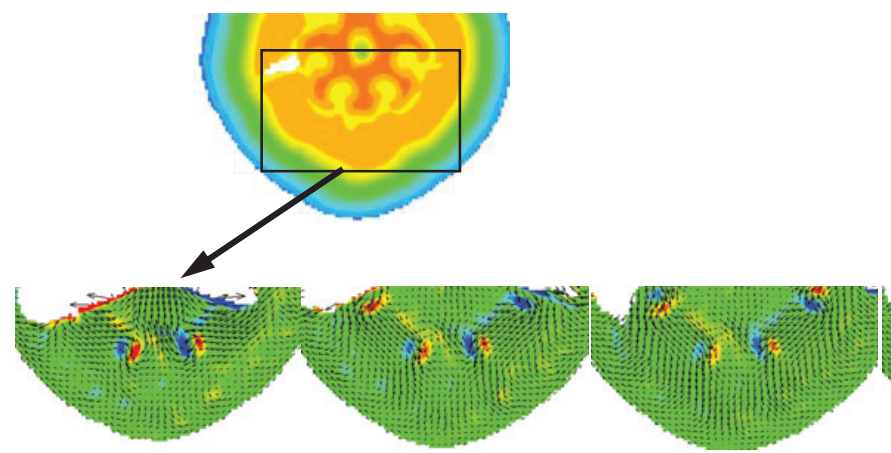

(a)
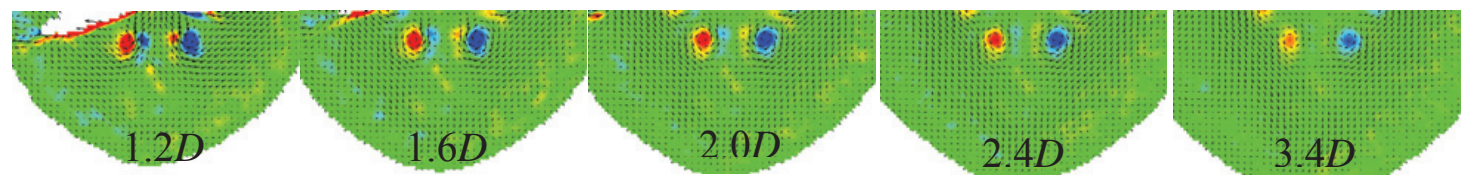

(b)
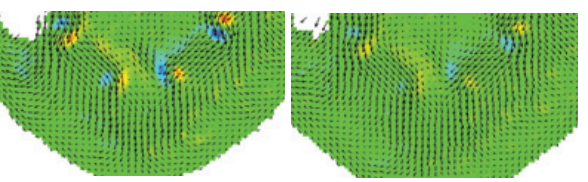

Figure 21. An exploded view of the streamwise vorticity contours and cross-stream velocity vectors obtained in the cross-stream planes indicated in the plots at the jet conditions in Fig. 18 for the steep injection nozzle with (a) IPR $=1.0$ and (b) $I P R=3.0$. The legend is the same as that used in Fig. 17. 



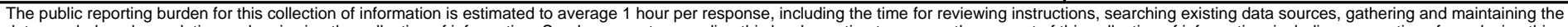

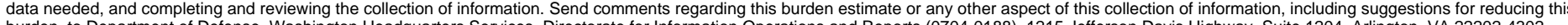

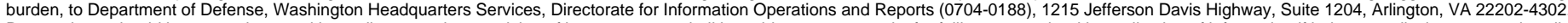

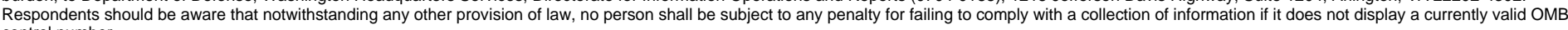

control number.
PLEASE DO NOT RETURN YOUR FORM TO THE ABOVE ADDRESS.

\begin{tabular}{l|l|l}
\hline $\begin{array}{l}\text { 1. REPORT DATE }(D D-M M-Y Y Y Y) \\
01-05-2012\end{array}$ & $\begin{array}{l}\text { 2. REPORT TYPE } \\
\text { Technical Memorandum }\end{array}$ & 3. DATES COVERED (FrOm - To)
\end{tabular}

4. TITLE AND SUBTITLE

A PIV Study of Slotted Air Injection For Jet Noise Reduction

5a. CONTRACT NUMBER

5b. GRANT NUMBER

5c. PROGRAM ELEMENT NUMBER

6. AUTHOR(S)
Henderson, Brenda, S.; Wernet, Mark, P.

\section{5d. PROJECT NUMBER}

5e. TASK NUMBER

5f. WORK UNIT NUMBER

WBS 984754.02.07.03.17.05

7. PERFORMING ORGANIZATION NAME(S) AND ADDRESS(ES)

National Aeronautics and Space Administration

John H. Glenn Research Center at Lewis Field

Cleveland, Ohio 44135-3191

\section{SPONSORING/MONITORING AGENCY NAME(S) AND ADDRESS(ES)}

National Aeronautics and Space Administration

Washington, DC 20546-0001
8. PERFORMING ORGANIZATION REPORT NUMBER

E-18006

\section{DISTRIBUTIONIAVAILABILITY STATEMENT}

Unclassified-Unlimited

Subject Category: 71

Available electronically at http://www.sti.nasa.gov

This publication is available from the NASA Center for AeroSpace Information, 443-757-5802

\section{SUPPLEMENTARY NOTES}

\section{ABSTRACT}

Results from acoustic and Particle Image Velocimetry (PIV) measurements are presented for single and dual-stream jets with fluidic injection on the core stream. The fluidic injection nozzles delivered air to the jet through slots on the interior of the nozzle at the nozzle trailing edge. The investigations include subsonic and supersonic jet conditions. Reductions in broadband shock noise and low frequency mixing noise were obtained with the introduction of fluidic injection on single stream jets. Fluidic injection was found to eliminate shock cells, increase jet mixing, and reduce turbulent kinetic energy levels near the end of the potential core. For dual-stream subsonic jets, the introduction of fluidic injection reduced low frequency noise in the peak jet noise direction and enhanced jet mixing. For dual-stream jets with supersonic fan streams and subsonic core streams, the introduction of fluidic injection in the core stream impacted the jet shock cell structure but had little effect on mixing between the core and fan streams.

\section{SUBJECT TERMS}

PIV; Slotted; Air injection; Jet noise reduction

\begin{tabular}{|c|c|c|c|c|c|}
\hline \multicolumn{3}{|c|}{ 16. SECURITY CLASSIFICATION OF: } & \multirow{2}{*}{$\begin{array}{l}\text { 17. LIMITATION OF } \\
\text { ABSTRACT } \\
\text { UU }\end{array}$} & \multirow{2}{*}{$\begin{array}{l}\text { 18. NUMBER } \\
\text { OF } \\
\text { PAGES } \\
24\end{array}$} & \multirow{2}{*}{$\begin{array}{l}\text { 19a. NAME OF RESPONSIBLE PERSON } \\
\text { STI Help Desk (email:help@sti.nasa.gov) } \\
\text { 19b. TELEPHONE NUMBER (include area code) } \\
\text { 443-757-5802 }\end{array}$} \\
\hline $\begin{array}{l}\text { a. REPORT } \\
\text { U }\end{array}$ & $\begin{array}{l}\text { b. ABSTRACT } \\
\text { U }\end{array}$ & $\begin{array}{l}\text { c. THIS } \\
\text { PAGE } \\
\text { U }\end{array}$ & & & \\
\hline
\end{tabular}



